
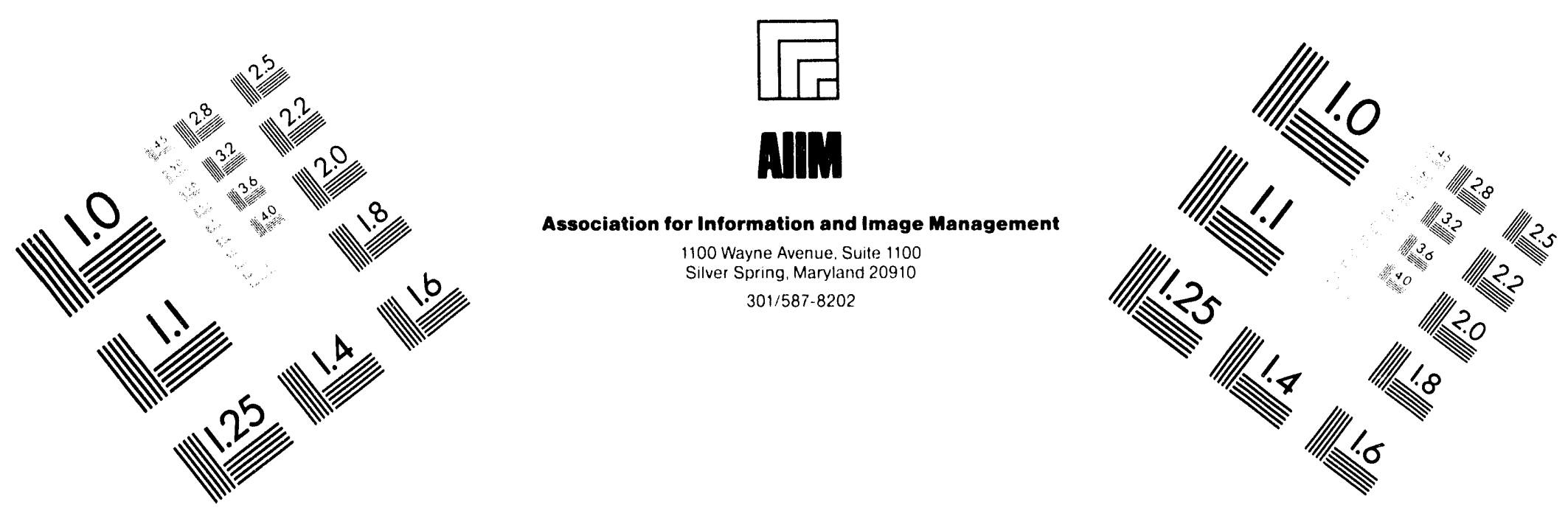

\title{
Centimeter
}

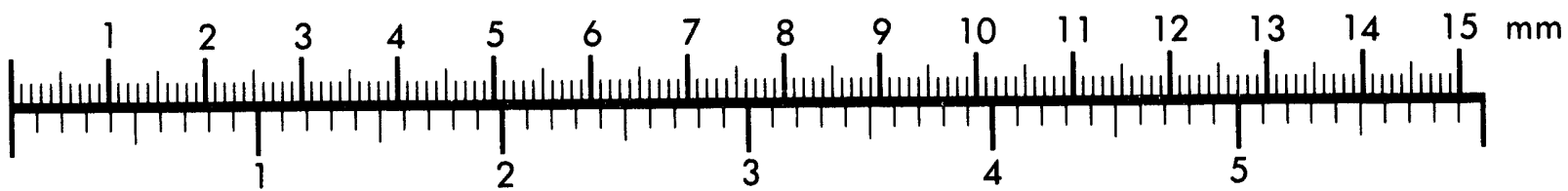
Inches
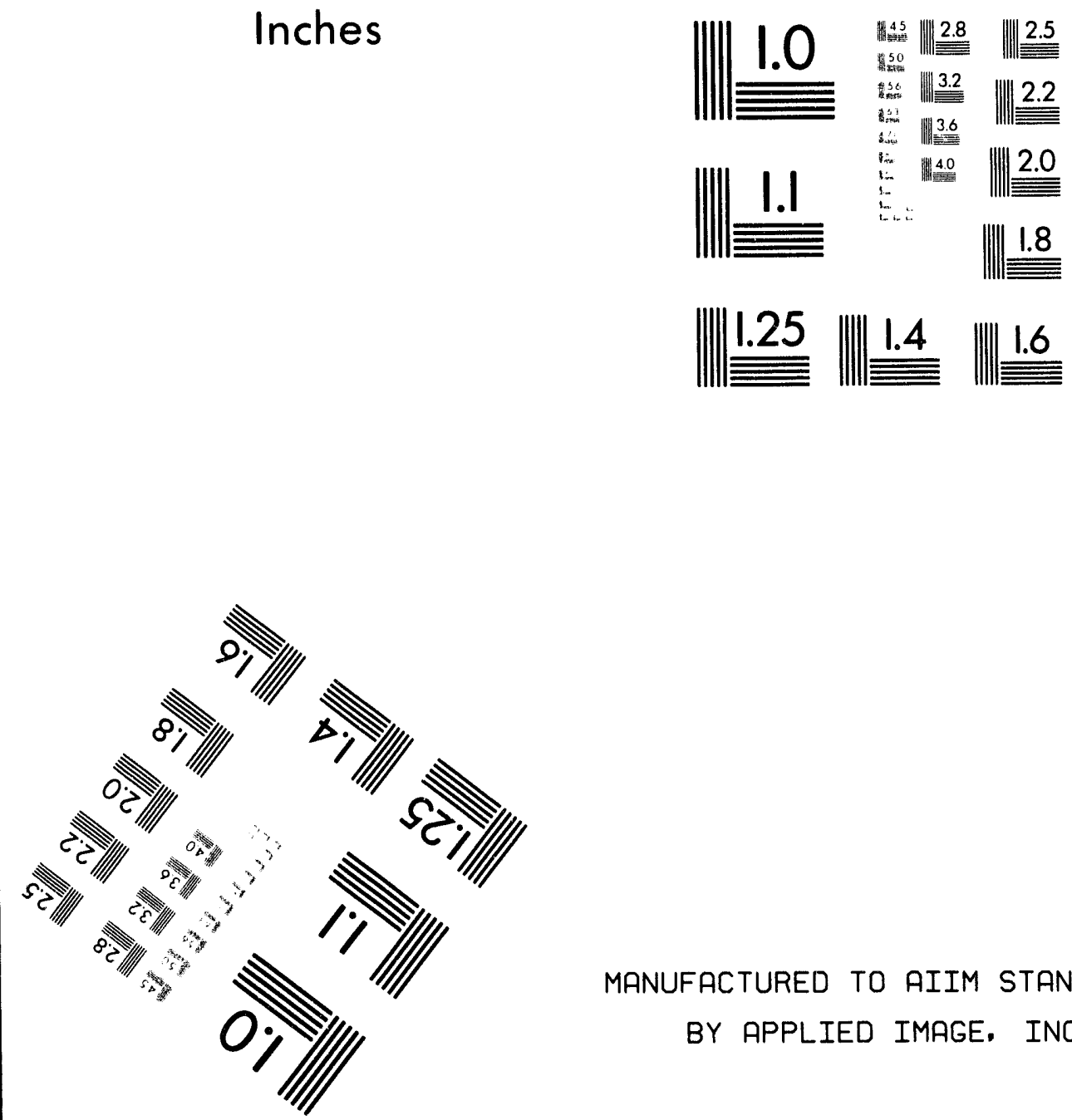

MANUFACTURED TO AIIM STANDARDS BY APPLIED IMAGE, INC.

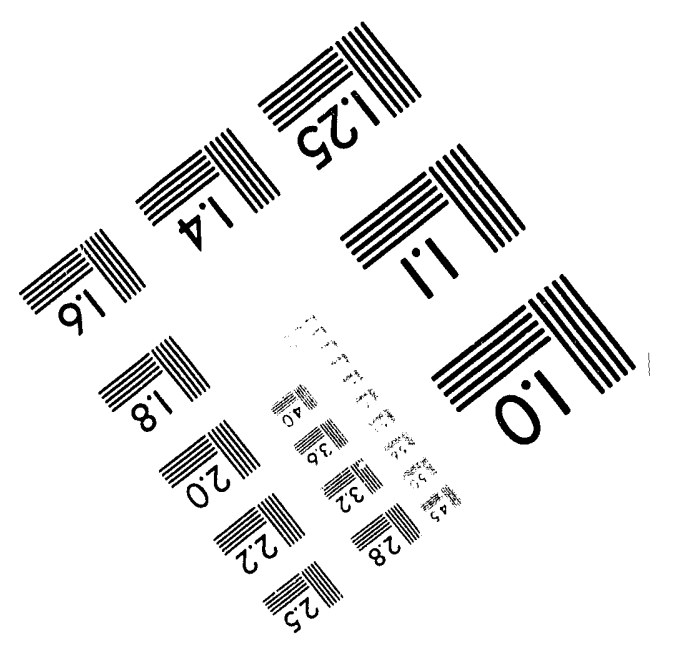



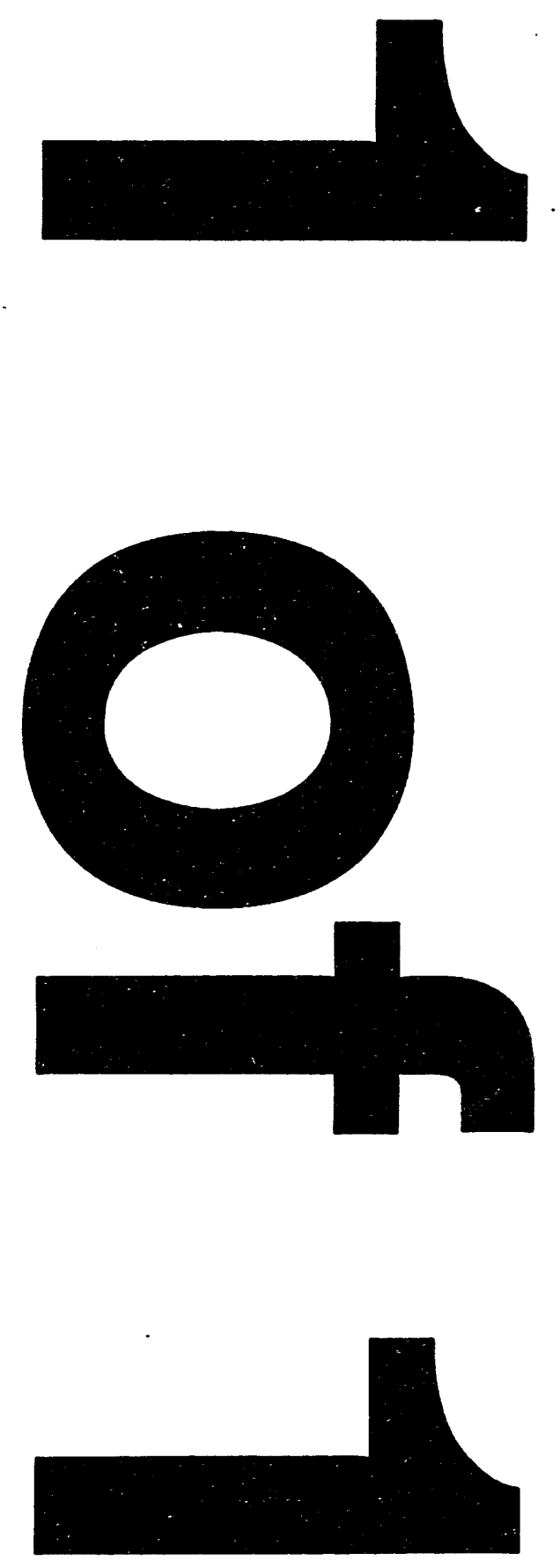
PNL-9740

UC-103

\section{Electrically Enhanced Fluidized Bed Heat Exchanger}

D. L. Lessor

R. J. Robertus

G. L. Roberts

May 1994

Prepared for the U.S. Department of Energy under Contract DE-AC06-76RLO 1830

Pacific Northwest Laboratory

Richland, Washington 99352 


\begin{abstract}
Our experiments have shown that a high level of electrical charging can be achieved in a fluidized bed of two resistive particle types; that bed stabilization rather than increased sensible heat transport dominates low frequency electric field effects on heat transfer with most bed loadings; and, hence, that applying an oscillatory potential difference between tubes or rods in a fluidized bed of two mutual contact-charging particle species gives reduced rather than improved heat transfer. Applying an oscillatory potential difference between rods in a bed of quartz particles fluidized alone did give improved heat transfer, however. With no electric field applied, most fluidized mixes were found to give higher heat transfer rates than the average of the values when each of the two species was fluidized alone. The high level of charging observed in some mixed beds may prove of interest for some air cleanup applications; our results show that simultaneous fluidization of pairs of bipolar charging materials of similar particle size is possible without excessive agglomeration. This would be important for air cleanup.
\end{abstract}




\section{Summary}

\section{Concept and Purpose of Project}

This project was an investigation of the electrically enhanced fluidized bed heat exchanger concept. The purpose of the electrically enhanced fluidized bed is to extract heat from a hot gas stream with minimal temperature drop and minimal hardware. The concept is to use the hot gas stream to fluidize a bed of two or more particle species which charge on contact, to apply an oscillatory electric potential difference between heat exchanger tubes which penetrate the bed, and thereby to enhance heat transfer. The oscillatory electric field was expected to cause oscillatory particle motion, to increase sensible heat transport, to erode gas boundary layers at tube surfaces, to improve thermal contact between particles and tubes by squeezing out gas layers, to replenish the particles in contact with the tubes every half cycle, and, by all these mechanisms, to enhance heat transfer. The improved heat transfer was expected to make heat recovery from marginally hot waste gas streams economically feasible.

\section{Achievements and Findings}

Our experiments have shown that a high level of electrical charging can be achieved in a fluidized bed of two resistive particle types; that bed stabilization rather than increased sensible heat transport dominates low frequency electric field effects on heat transfer with most bed loadings; and, hence, that the AC-enhanced fluidized bed as originally envisioned does not improve fluidized bed heat transfer in a useful way. While some heat transfer enhancement, not necessarily attributable to bipolar charging, appears in some fluidized mixes, it seems insignificant economically. The high level of charging observed in some mixed beds may prove of interest for some air cleanup applications; our results show that simultaneous fluidization of pairs of bipolar charging materials of similar particle size is possible without excessive agglomeration. This would be important for air cleanup.

U. S. Patent 4,890,667 was issued January 2,1990 , for the electrically enhanced fluidized bed concept, but we now anticipate no licensing.

Major findings of this study include:

1. Intense contact charging can be achieved in fluidized beds loaded with particles of pairs of materials that are triboelectrically dissimilar and electrically resistive. Glass, aluminum oxide, magnesium oxide, and quartz are suitable materials. Teflon ${ }^{(a)}$ proved less satisfactory.

2. Positive enhancement of heat transfer by applying an oscillatory electric field was achieved for only one of the bed loadings tested, that of quartz fluidized alone. Paired materials showed inhibited heat transfer when an electric field at $20 \mathrm{~Hz}$ was applied. The inhibition at $40 \mathrm{~Hz}$ is approximately $50 \%$ of that at $20 \mathrm{~Hz}$.

(a) Teflon is a registered trademark of E.I. duPont de Nemours, Inc. 
3. Even in fluidized quartz, the heat transfer enhancement under an applied electric field was too small to be of economic interest. This enhancement may result from a field-induced rolling contact of particles which charge differently on different faces. For pairs of contact-charging materials fluidized together, heat transfer inhibition under an applied electrical potential difference between immersed tubes probably results from bed stabilization by the electric field.

4. In the absence of an applied electric field, we found reproducible departures of heat transfer coefficients from values given by standard correlations. The departures of the measured heat transfer coefficient from standard correlations appear to be related to particle roundness, which influences the thermal resistance of the gas film between the particle and the rod surface during impact.

5. In the absence of an applied field, heat transfer coefficients between the gas stream and rods inserted in the fluidized beds were usually higher for a mix of two of the particle types than the average of the values for the two particle types fluidized separately. This improved heat transfer for the mix did not seem to be related to charging characteristics, however.

6. A high heat transfer coefficient for a fluidized particle mix is potentially useful in fluidized beds in which gas cleanup is also desired. A mix of two particle types which charge each other when fluidized could remove gas-borne particulates from the fluidizing gases and adsorb multiple species of noxious gases, which also offering good heat recovery from the fluidizing gas stream.

7. Simultaneous fluidization and charge spectrum measurement techniques reported here should be useful in insulator-insulator charging studies. These measurements have been much more difficult to quantify than insulator-conductor charging. 


\section{Contents}

Abstract $\ldots \ldots \ldots \ldots \ldots \ldots \ldots \ldots \ldots \ldots \ldots \ldots \ldots \ldots \ldots \ldots$ iii

Summary $\ldots \ldots \ldots \ldots \ldots \ldots \ldots \ldots \ldots \ldots \ldots \ldots \ldots \ldots \ldots$

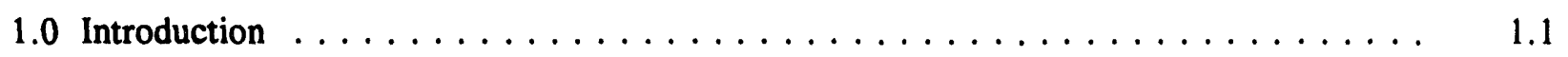

1.1 Project Goals $\ldots \ldots \ldots \ldots \ldots \ldots \ldots \ldots \ldots \ldots \ldots \ldots \ldots \ldots$

1.2 Test Design, Construction, and Checkout $\ldots \ldots \ldots \ldots \ldots \ldots \ldots \ldots$

1.3 Preliminary Experiments and Results $\ldots \ldots \ldots \ldots \ldots \ldots \ldots \ldots \ldots$

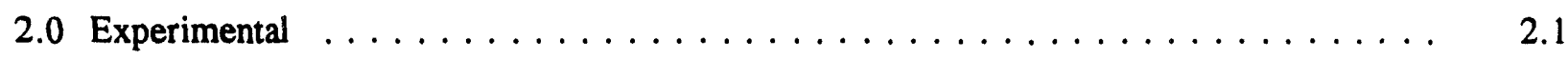

2.1 Hardware and Experimental Approach $\ldots \ldots \ldots \ldots \ldots \ldots \ldots \ldots \ldots$

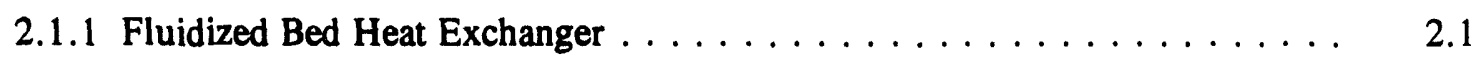

2.1.2 Electrostatic Charge Separation Device $\ldots \ldots \ldots \ldots \ldots \ldots \ldots . \ldots .2$

2.1 .3 Approach $\ldots \ldots \ldots \ldots \ldots \ldots \ldots \ldots \ldots \ldots \ldots \ldots \ldots$

2.2 Operational Insights $\ldots \ldots \ldots \ldots \ldots \ldots \ldots \ldots \ldots \ldots \ldots \ldots \ldots$

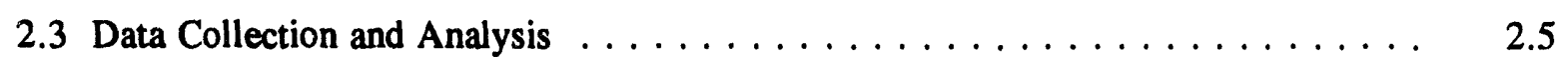

2.3.1 Charge Measurements $\ldots \ldots \ldots \ldots \ldots \ldots \ldots \ldots \ldots \ldots \ldots$

2.3.2 Fluidized Bed Heat Exchanger Tests $\ldots \ldots \ldots \ldots \ldots \ldots \ldots \ldots$

2.3.3 Charge Spectrum Analysis $\ldots \ldots \ldots \ldots \ldots \ldots \ldots \ldots \ldots \ldots \ldots$

2.3.4 Heat Transfer Analysis $\ldots \ldots \ldots \ldots \ldots \ldots \ldots \ldots \ldots \ldots$

3.0 Clarifying Investigations and Inferences $\ldots \ldots \ldots \ldots \ldots \ldots \ldots \ldots \ldots$

3.1 Particle Charging $\ldots \ldots \ldots \ldots \ldots \ldots \ldots \ldots \ldots \ldots \ldots \ldots \ldots \ldots$

3.2 Charge Transport Phenomena $\ldots \ldots \ldots \ldots \ldots \ldots \ldots \ldots \ldots \ldots \ldots$

vii 
3.3 Heat Transfer Phenomena $\ldots \ldots \ldots \ldots \ldots \ldots \ldots \ldots \ldots \ldots \ldots$

3.3.1 Axial Heat Flow Corrections $\ldots \ldots \ldots \ldots \ldots \ldots \ldots \ldots \ldots$

3.3.2 Electric Field Effects on Heat Transfer $\ldots \ldots \ldots \ldots \ldots \ldots$

3.3.3 Zero Field Effects from Bipolar Charging $\ldots \ldots \ldots \ldots \ldots \ldots \ldots$

4.0 Economic Assessment $\ldots \ldots \ldots \ldots \ldots \ldots \ldots \ldots \ldots \ldots \ldots \ldots$

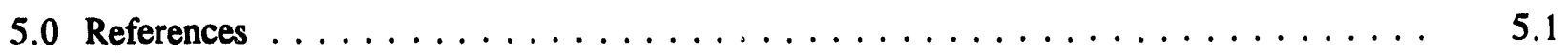

viii 


\section{Figures}

2.1 Electrically Enhanced Fluidized Bed Heat Exchanger Equipment Layout Diagram . . . . 2.1

2.2 Some Construction Details of the Fluidized Bed Heat Exchanger . . . . . . . . . 2.2

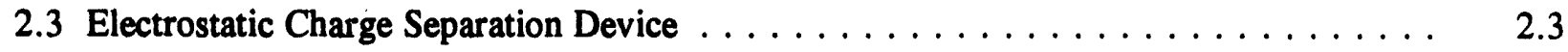

2.4 Distribution of Unfluidized Particles in an Electric Field $\ldots \ldots \ldots \ldots \ldots \ldots \ldots$

2.5 Distribution of Particles in an Electric Field After Minimal Contact Charging $\ldots \ldots \ldots$

2.6 Particle Distribution in an Electric Field After Steady State Contact Charging $\ldots \ldots$. . . 2.9

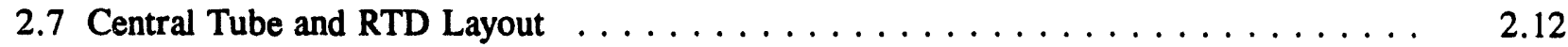

2.8 Temperature Profiles Around Center Tube $\ldots \ldots \ldots \ldots \ldots \ldots \ldots$

2.9 Temperature Profiles for AC and DC Operation $\ldots \ldots \ldots \ldots \ldots \ldots$

2.10a Temperature Gradients with No Field, AC, then DC Field Applied . . . . . . . . 2.15

$2.10 \mathrm{~b}$ Temperature Gradients with DC Field Applied $\ldots \ldots \ldots \ldots$

3.1 Higher Resolution Postfluidization Deflection Spectrum of $\mathrm{Al}_{2} \mathrm{O}_{3}$-Glass

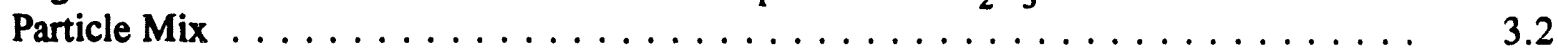




\section{Tables}

2.1 Data for Electrostatic Charging Experiments $\ldots \ldots \ldots \ldots \ldots$

2.2 Charge-to-Mass Ratios Associated with Sample Boats in Figures 2.4, 2.5, and $2.6 \ldots 2.10$

2.3 Input Data and Results of Heat Transfer Analyses $\ldots \ldots \ldots \ldots \ldots \ldots$

3.1 Parameters Varied in Fluidized Bed Heat Transfer Experiments $\ldots \ldots \ldots \ldots . \ldots$

3.2 Roundness Characteristics of Glass Beads and Quartz Particles Used

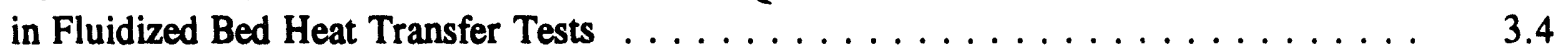

3.3 Heat Transfer Coefficients $\mathrm{h}\left(\mathrm{BTU} / \mathrm{ft}^{2}-\mathrm{hr}-^{\circ} \mathrm{F}\right)$ of Glass Beads and Quartz Particles Used in Fluidized Bed Heat Transfer Tests at Varying Applied Potentials V(kV,

Peak-to-Peak) and Frequency $\mathbf{f}(\mathrm{Hz}) \ldots \ldots \ldots \ldots \ldots \ldots \ldots \ldots$ 


\subsection{Introduction}

\subsection{Project Goals}

The objective of this project was to demonstrate the contact-charging, electrically enhanced fluidized bed heat exchanger concept. In this concept, bed particles are of two material types, which acquire different signs of electric charge on contact with each other or with materials present. An alternating potential difference between immersed heat exchanger tubes is applied to increase particle motion, erode thermally-resistive boundary layers, and improve thermal contact between particles and the tubes. All three of these effects should increase the bed-to-tube heat transfer rate. Increased heat transfer rates should allow lower equipment costs, smaller pressure drops, and better energy recovery. To test the concept, a series of bench-scale experiments and a modeling effort were performed. The objectives of this effort were to 1) demonstrate that heat transfer can be enhanced, and 2) provide insights for the choices of material composition, particle size, field strength, frequency, and flow velocity to optimize the enhancement.

\subsection{Test Design, Construction, and Checkout}

An experimental fluidized bed test facility, instrumented to study electrical effects, was designed and constructed. Described in Section 2.0, it features: heater rods, which also serve as electrodes, immersed in the fluidized particle medium; temperature monitoring of the heater rods and of the gas phase; monitoring of heater power, gas flow, voltage and current; and recording of this and other information with a computer-based data acquisition system.

The modeling effort emphasized sensible heat transport enhancement as the major phenomenon of interest, and developed criteria for electrical resistivity, thermal conductivity, charge-to-mass ratio, particle size, field strength, frequency, and other parameters. From these criteria, tentative choices were made of particle pairs for experimental testing.

\subsection{Preliminary Experiments and Results}

Activities in FY 90 emphasized: 1) improving the selection of candidate particle pairs, 2) characterizing their triboelectric behavior, 3) performing heat transfer tests in the fluidized bed under varying conditions of bed loading, field strength, and field frequency, and 4) acquiring operating experience and insights for possible commercial applications.

Promising particle materials were selected, based on criteria of electrical resistivity, thermal conductivity, hardness, and temperature stability. One previous choice, dolomite, was ruled out because of its tendency to crumble. Charge measurements on fluidized particles with an instrument designed and built in house (which we have termed a "deflectometer") showed encouragingly high electrical charging for pairs of dissimilar electrically resistive particle materials which had been fluidized together. Pairwise combinations of glass beads, $\mathrm{MgO}, \mathrm{Al}_{2} \mathrm{O}_{3}$, and Teflon exhibited good charging 
properties, but Teflon had an unacceptable tendency to segregate from the other materials. The particle material selection process and charge measurements are described in Section 2.0.

As we had predicted, heat transfer was inhibited by high voltage DC applied between heater rods immersed in a bipolar-charging two-material fluidized bed, but with an unexpected dependence on polarity for the alumina-glass combination. AC field tests in this alumina-glass bed also showed a heat transfer inhibition, contrary to the enhancement that was expected. The maximum inhibition effect occurs at $10-20 \mathrm{~Hz}$. Heat transfer returns to approximately the "no field" rates when the $20 \mathrm{kV}$ field frequency is increased from $20 \mathrm{~Hz}$ to $100 \mathrm{~Hz}$. We hypothesize that inhibition occurs because:

1) at the low void fraction conditions of the experiment, the bed particles experience strong mechanical drag which resists counterflow of positive and negative particles;

2) the glass particles may lose charge too quickly during contact with the heater rod electrodes, so that they are not pushed away when the field changes sign, but instead build up an insulating layer; and

3) the low frequency electric field, like DC, makes the bed more rigid and thus inhibits heat transfer.

Heat transfer tests and their analysis are described in Section 2. Inferences, hypotheses, and experiments conducted to test them are described in Section 3. Specifically, tests using $\mathrm{MgO}$ and $\mathrm{Al}_{2} \mathrm{O}_{3}$ instead of glass and $\mathrm{Al}_{2} \mathrm{O}_{3}$, and experiments using higher void fractions were proposed to test the hypotheses of charge loss from glass on electrode contact and of excessive drag at low void fractions.

The hypothesis of charge loss by the glass is consistent with the polarity dependence of heat transfer when the fields applied are DC. In our charge measurements ("deflectometer tests"), glass charged negatively when fluidized with $\mathrm{Al}_{2} \mathrm{O}_{3}$. When a particular electrode (heater rod) was at positive relative potential (and hence should coat with glass), the heat transfer inhibition was small. When the electrode was negative (and hence should coat with $\mathrm{Al}_{2} \mathrm{O}_{3}$ ), a strong heat transfer inhibition occurred. This is consistent with the glass particles forming a less permanent layer than the $\mathrm{Al}_{2} \mathrm{O}_{3}$, which is what would occur if the glass particles lose charge.

With no applied electric field, our heat transfer measurements in these pilot experiments seemed to indicate higher heat transfer coefficients than predicted by standard correlations, due to the mere presence of bipolar charge in the fluidized bed. Such an enhancement would be significant for both its theoretical implications and its economic impact. It suggested that the dominant mechanism for heat transfer enhancement is improved particle-to-wall thermal contact, and not increased sensible heat transport. It further implied an opportunity to improve heat recovery with a safer, more passive, and less costly arrangement than the high voltage AC system originally envisioned. Because of its importance and its difficulty (not unlike calorimetric tests of cold fusion), this result was regarded as tentative and in urgent need of further verification. Further tests of this effect, which largely disproved it, are described in Section 3.0. 
The heat transfer tests yielded four important insights:

1) mobility of electric charge deposited on the fluidized particles can increase arcing problems;

2) such charge mobility appears to be related to impurities in otherwise electrically resistive materials, and hence preventive measures are possible;

3) ballast resistors can limit damage from electrical arcing; and

4) a passive system which does not require continuously applied high voltage would be advantageous.

Arcing problems are discussed in Section 2.0, and inferences from them are discussed in Section 3.0. 


\subsection{Experimental}

\subsection{Hardware and Experimental Approach}

\subsubsection{Fluidized Bed Heat Exchanger}

The fluidized bed heat exchanger and supporting equipment are shown in Figure 2.1. Figure 2.2 gives an overall view of the heat exchanger alone.

The heat exchanger consists of 25 one-inch rods in a square array on 1.25 inch centers. All the rods are electrically heated. The rods serve the dual functions of heat source and electrodes for the electric field. The center rod (row 3, column 3 ) is grounded. Four adjacent tubes (immediately above, below, to the left, and to the right of the center tube) are connected to the high voltage power supply. Grounded and "hot" tubes then alternate within the array so that the total configuration includes 13 grounded tubes and 12 hot ones. This means that, for any tube in the inner $3 \times 3$ array, all its nearest neighbors are of opposite polarity. Thus the electric field configuration near the center of the bed should be similar for all tubes.

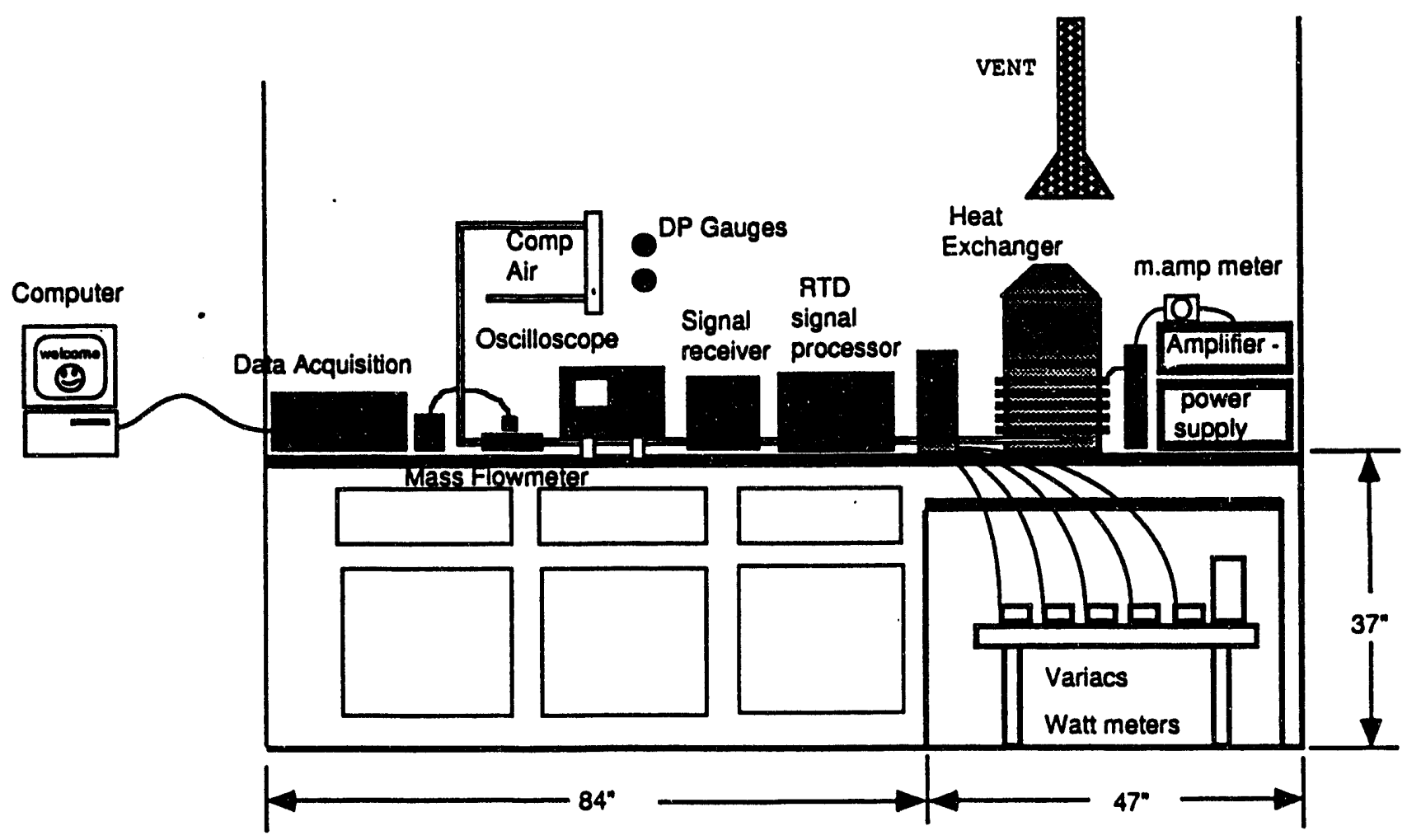

Figure 2.1. Electrically Enhanced Fluidized Bed Heat Exchanger Equipment Layout Diagram 

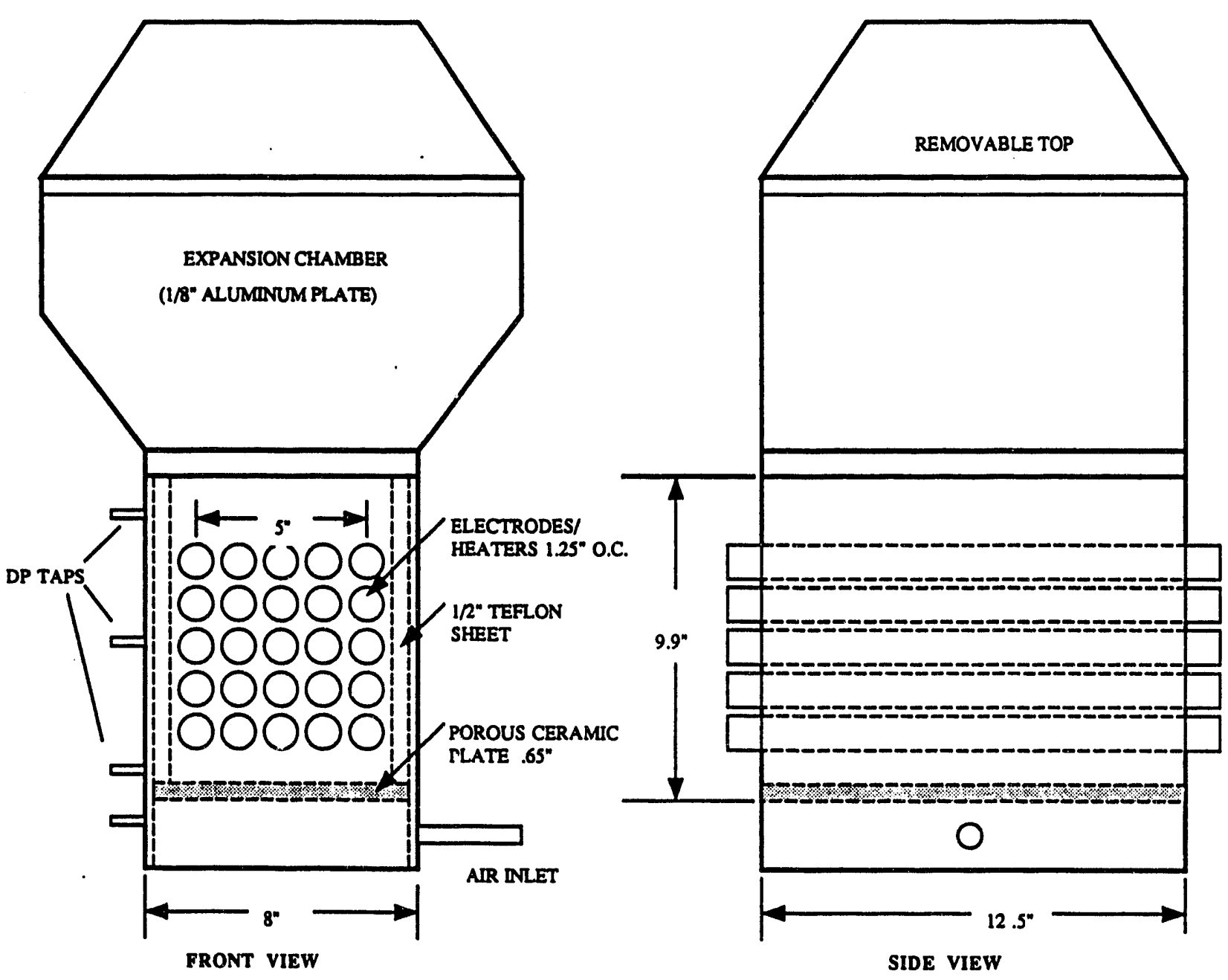

Figure 2.2. Some Construction Details of the Fluidized Bed Heat Exchanger

All nine inner tubes are notched to accommodate an RTD (Resistance Thermal Device) which measures the tube skin temperature. Five more RTD's extend into the gas stream (at various positions depending on the tests being run) to measure gas temperatures in the fluidized bed. The heating elements in each rod are rated at 310 watts with 240 VAC input. They are operated on 110 VAC, with variacs to control the applied voltage. For tests to date, heat input has been sufficient with about 80 VAC applied.

The high voltage power supply is a 1000:1 voltage amplifier which can follow sinusoidal or square wave input over a wide frequency range. Its maximum output is $20 \mathrm{kV}$ peak to peak $(0$ to $\pm 10 \mathrm{kV}$ amplitude).

\subsubsection{Electrostatic Charge Separation Device (Deflectometer)}

The deflectometer is designed to measure charge distribution on particles of roughly uniform size and mass. The particles charge in a small fluidizing chamber (a plexiglas tube 2.5 inches ID by 12.4 
inches high), which sits above the apparatus shown in Figure 2.3. For a given contact charging test, approximately equal weights (between 200 and 300 grams) of two different particles are added to the fluidizing chamber. Charging can be followed as a function of time (within limits because sampling times are on the order of 1-2 minutes) or, more usually, is measured at steady state (fully charged) conditions. Calculations show that fully charged conditions occur in less than 20 minutes for most particle pairs.

Charge distributions are measured by dropping a small sample ( 5 to 10 grams) of the bed particles through a Teflon valve into the space between the two aluminum plates shown in Figure 2.3. One plate is grounded and the other is maintained at a high negative voltage (up to $-50 \mathrm{kV} \mathrm{DC}$ ). The sample gets distributed by the electric field into the nine sample boats at the bottom of the electrodes. The weight of particles collected as a function of position between electrodes can be determined from the sample weights in each boat.

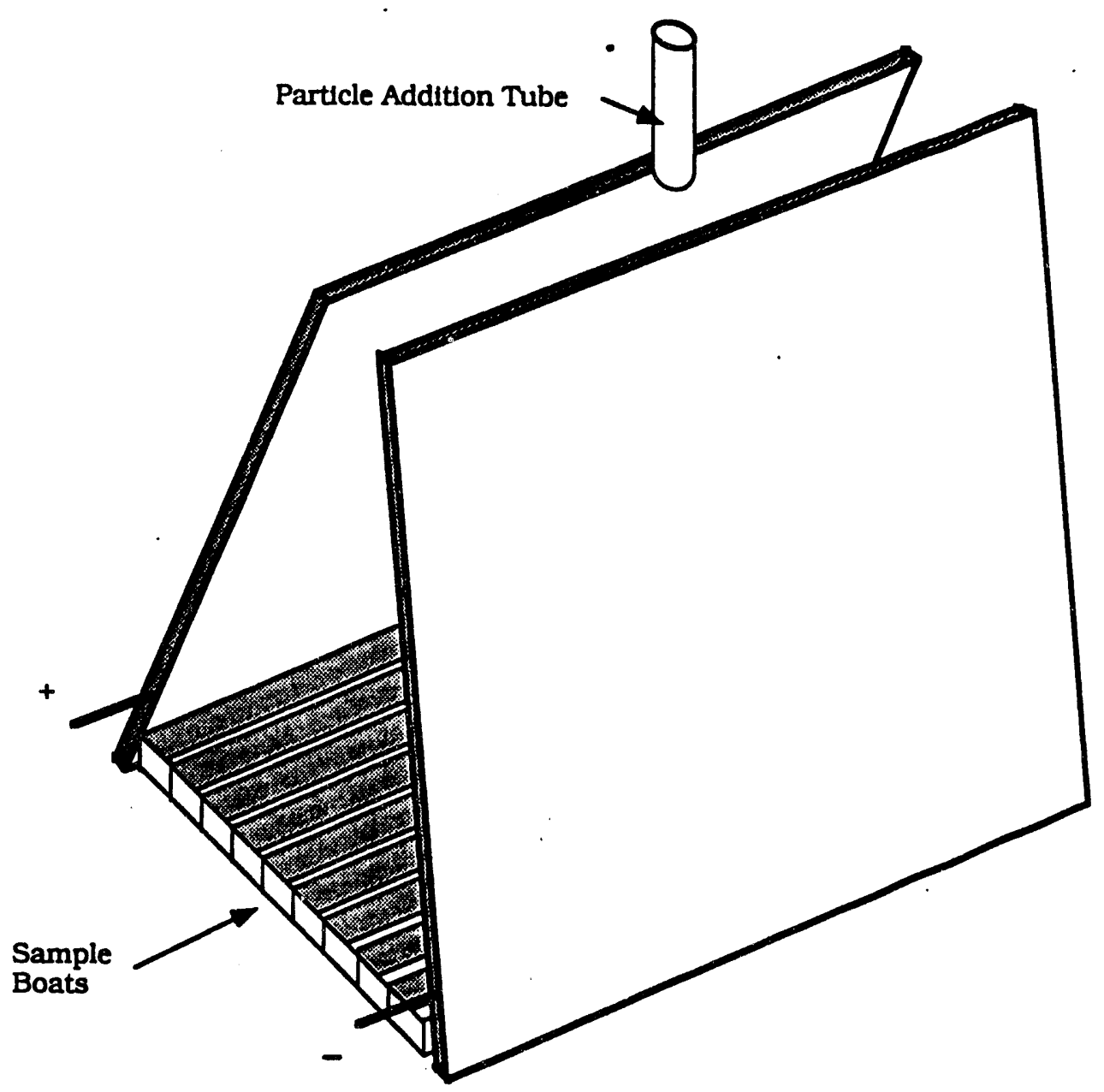

Figure 2.3. Electrostatic Charge Separation Device 
The dimensions of the electrode plates were selected so the electric field can be adequately modeled as two-dimensional. Another modeling consideration sets the height of the sample valve above the electrodes. This distance was set so that particles would approach their terminal velocities before dropping between the electrodes, although the analysis used calculated velocities and trajectories based on acceleration and drag. Electrode spacing at the top of the deflector, distance of the sample valve above the electrodes, and voltage applied to the negative plate were all adjusted as necessary to get useful particle size spectrum information.

\subsubsection{Approach}

Significant effort was expended to find particle materials which might be used commercially. This means they should be cheap, non-hazardous, stable at high temperatures, and yet charge well by contact with other particles. The literature cites experiments which show that many polymers will charge triboelectrically. Most polymers, however, melt or soften at unacceptably low temperatures. Teflon seemed to be the only polymer with high enough temperature stability to warrant consideration. Teflon particles also acquire charge easily and retain it for long periods.

Literature searches revealed several other materials with high electrical resistivity, at least moderate thermal conductivity, and fair temperature stability, but their triboelectric properties were usually unknown. Glass and quartz were the only two that were well studied. Given this lack of information, we decided it was imperative to build an instrument which could quickly and at least semiquantitatively examine the charging characteristics of particle pairs.

The particles to be tested were first examined by screening chemical and mineral handbook information. Intuitively, particles with high thermal conductivity and high electrical resistivity are desirable. Preliminary calculations set the "desirable" resistivity at $6.3 \times 10^{10} \mathrm{ohm}-\mathrm{cm}$ or greater, and the thermal conductivity at $.0045 \mathrm{cal} / \mathrm{sec}-\mathrm{cm}-{ }^{\circ} \mathrm{K}$ or greater. The thermal conductivity requirement is set by the thermal relaxation time for particles of appropriate size $(\sim 0.1$ to $0.15 \mathrm{~mm}$ diameter), which should be less than a quarter period at $20 \mathrm{~Hz}$.

After the screening identified at least three candidate material pairs, tests began in the fluidized bed heat exchanger. The intent was to first show that the electric field did enhance heat transfer characteristics of the fluidized bed, under conditions calculated as reasonable. Later runs were intended to vary the voltage, frequency, and fluidizing velocity to optimize the enhancement effect. These later runs were also intended to provide engineering data for future economic analyses. Because enhancement effects did not occur as anticipated, effort was redirected to find materials and conditions for which enhancement occurs, and to explain and clarify the results found.

\subsection{Operational Insights}

Finding suitable bed materials was a significant challenge. Teflon was an early "preferred" material, but it proved very difficult to work with. It was virtually impossible to screen Teflon in the 100120 mesh size range we wanted to use. Static charging caused the Tefion to cling to the screens rather than fall through the openings. 
During the early charge separation measurements (using 70 mesh material), significant amounts of Teflon would collide with the electrode before falling into a sample boat. This indicated high electrical charging of the Tefion. Measurements with lower field strengths and wider plate separations did allow some quantitative measurements of the high charge level. Unfortunately, Teflon's agglomeration tendency and its charge retention characteristics ultimately made it impractical to use in the heat exchanger system. Other polymers such as nylon and methyl methacrylate were considered, but were rejected because of their low softening (melting) points.

With the help of the deflectometer, we identified magnesia $(\mathrm{MgO})$, alumina $\left(\mathrm{Al}_{2} \mathrm{O}_{3}\right)$, and glass in any paired combination as good triboelectrically charging materials. The first heat exchanger tests were with some readily available $\mathrm{Al}_{2} \mathrm{O}_{3}$ and glass particles. During the first attempt, severe arcing occurred prior to reaching $7 \mathrm{kV}$ peak-to-peak (p-p). The arcing damaged all pieces of electronic equipment except the computer. Some repairs were necessary.

Thereafter, the instrumentation was protected by adding ballast resistors ( $30 \mathrm{meg}$-ohm initially) to the ground loop of the high voltage amplifier. With this protection, arcing still occurred at voltages as low as $4 \mathrm{kV}$ p-p, but it no longer damaged the instrumentation. When the arcing did occur, it was not immediate, but happened after the bed had been fluidized for about 8-10 minutes. We therefore deduce that the arcing is due to the mobility of added charge, and not to intrinsic electrical conductivity. Charge motion either on the surface or within fluidized particles would make each particle a more nearly equipotential region, and would thereby increase the amount of potential drop that occurs in the space between particles. Hence, the charge motion would tend to promote electrical breakdown. We discovered at this point that our alumina particles were contaminated with about 1 weight percent titanium. Procuring high purity alumina allowed us to operate up to the maximum voltage of the amplifier $(20 \mathrm{kV} \mathrm{p}-\mathrm{p})$ without arcing.

\subsection{Data Collection and Analysis}

\subsubsection{Charge Measurements}

Data was collected on all six possible particle pairs from the four starting materials: glass, alumina, magnesia, and Teflon. Two other materials, quartz and dolomite, were checked while debugging the device, but results were not as promising.

Table 2.1 gives the relevant operating parameters for charging and then separating the six particle pairs in the deflectometer. Figures 2.4 through 2.6 show the separations achieved for one pair of materials as a function of time. (The plots show weight percents for each of the particle pairs independently, i.e., total weight $\%$ glass $=100 \%$, and total weight $\%$ alumina $=100 \%$ ). The sample . boats were examined visually with magnifying glasses to determine the fraction of each pair in a particular sample boat. Figure 2.4 shows the amounts of glass and alumina collected before fluidization. Figures 2.5 and 2.6 show separation after $\sim 2$ minutes and $\sim 50$ minutes of fluidization, respectively.

A computation of particle trajectories, based on known plate geometry, applied potential difference, and particle release point, allowed calculation of a range of charge-to-mass ratios $\left(q / m_{p}\right)$ for each sample boat for each material. These $q / m_{p}$ values are shown in Table 2.2 for the tests shown in Figures 2.4, 2.5 and 2.6. Clearly, the charging is a time dependent phenomenon. The excellent 
Table 2.1. Data for Electrostatic Charging Experiments

\begin{tabular}{|c|c|c|c|c|c|c|c|c|c|c|}
\hline$N$ & $\begin{array}{l}\text { Positive } \\
\text { Particle }\end{array}$ & $\begin{array}{c}\text { Particle Size } \\
\text { (average) } \\
\text { (mm) }\end{array}$ & $\begin{array}{l}\text { Particle } \\
\text { Density } \\
\text { (g/cm) }\end{array}$ & $\begin{array}{c}\text { Negative } \\
\text { Particle }\end{array}$ & $\begin{array}{c}\text { Particle Size } \\
\text { (average) } \\
\text { (mm) }\end{array}$ & $\begin{array}{l}\text { Particle } \\
\text { Density } \\
\text { (g/cm) }\end{array}$ & $\begin{array}{c}\text { Distance Between } \\
\text { Electrodes at Top } \\
\text { (cm) }\end{array}$ & $\begin{array}{c}\text { Distance Between } \\
\text { Electrodes at Bottom } \\
\text { (cm) }\end{array}$ & $\begin{array}{c}\text { Valve Distance } \\
\text { Above Plates } \\
\text { (cm) } \\
\end{array}$ & $\begin{array}{c}\text { Voltage } \\
\text { Between } \\
\text { Electrodes } \\
\text { (kV) } \\
\end{array}$ \\
\hline & Teflon & 0.180 & 2.20 & Magnesia & 0.127 & 3.58 & 5.9 & 22.3 & 11.9 & 7.5 \\
\hline & Tefion & 0.359 & 2.20 & Alumine & 0.127 & 3.50 & 5.9 & 22.3 & 11.9 & 7.5 \\
\hline & Tefion & 0.180 & 2.20 & Glass & 0.127 & 2.60 & 5.9 & 22.3 & 11.9 & 7.5 \\
\hline & Magnesia & 0.127 & 3.58 & Glass & 0.127 & 2.60 & 2.5 & 20.8 & 11.4 & 15.0 \\
\hline & Magnesia & 0.127 & 3.58 & Alumina & 0.127 & 3.50 & 2.5 & 20.8 & 11.4 & 15.0 \\
\hline & Alumina & 0.127 & 3.50 & Glass & 0.127 & 2.60 & 2.5 & 20.8 & 11.4 & 15.0 \\
\hline
\end{tabular}



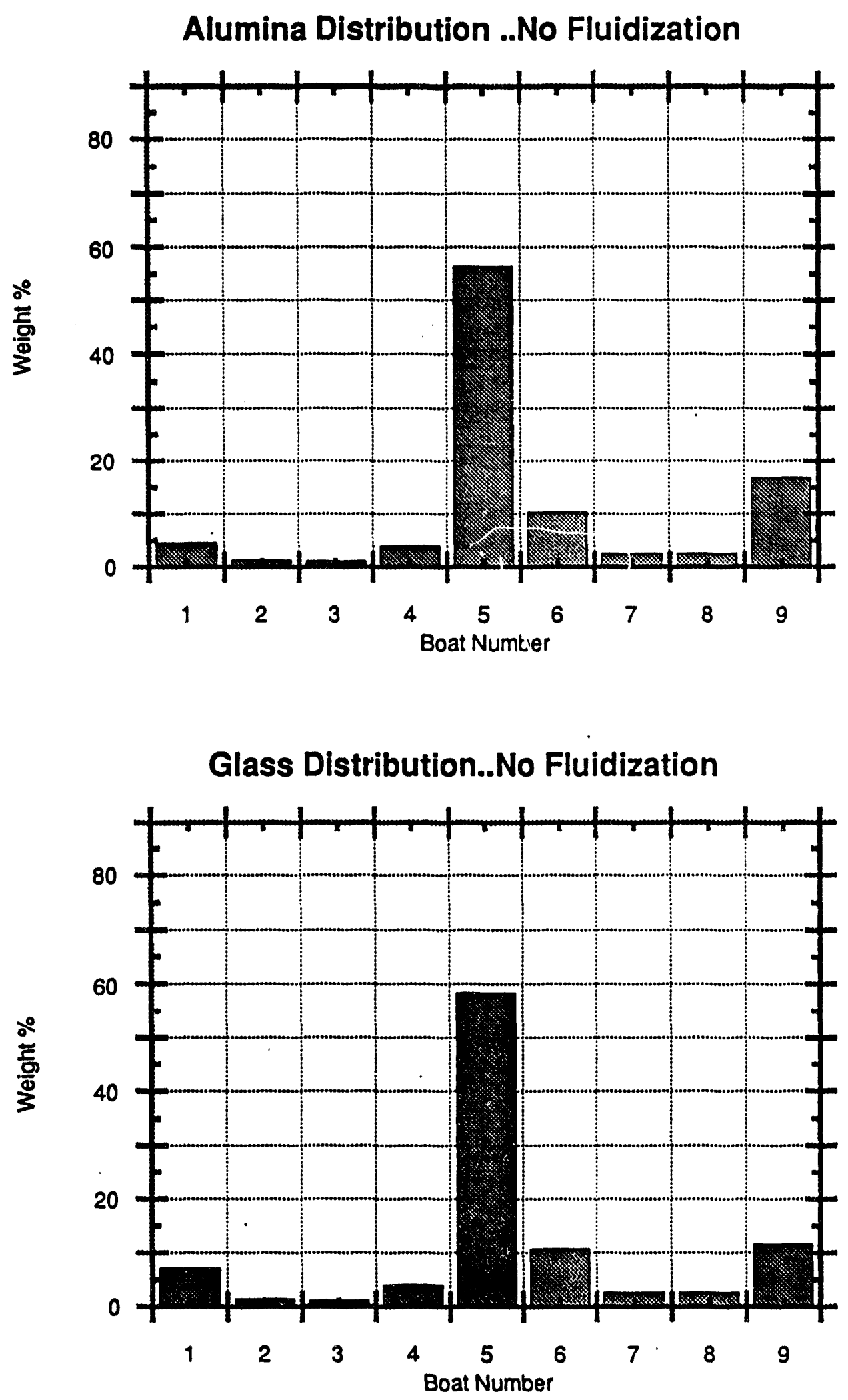

Figure 2.4. Distribution of Unfluidized Particles in an Electric Field 

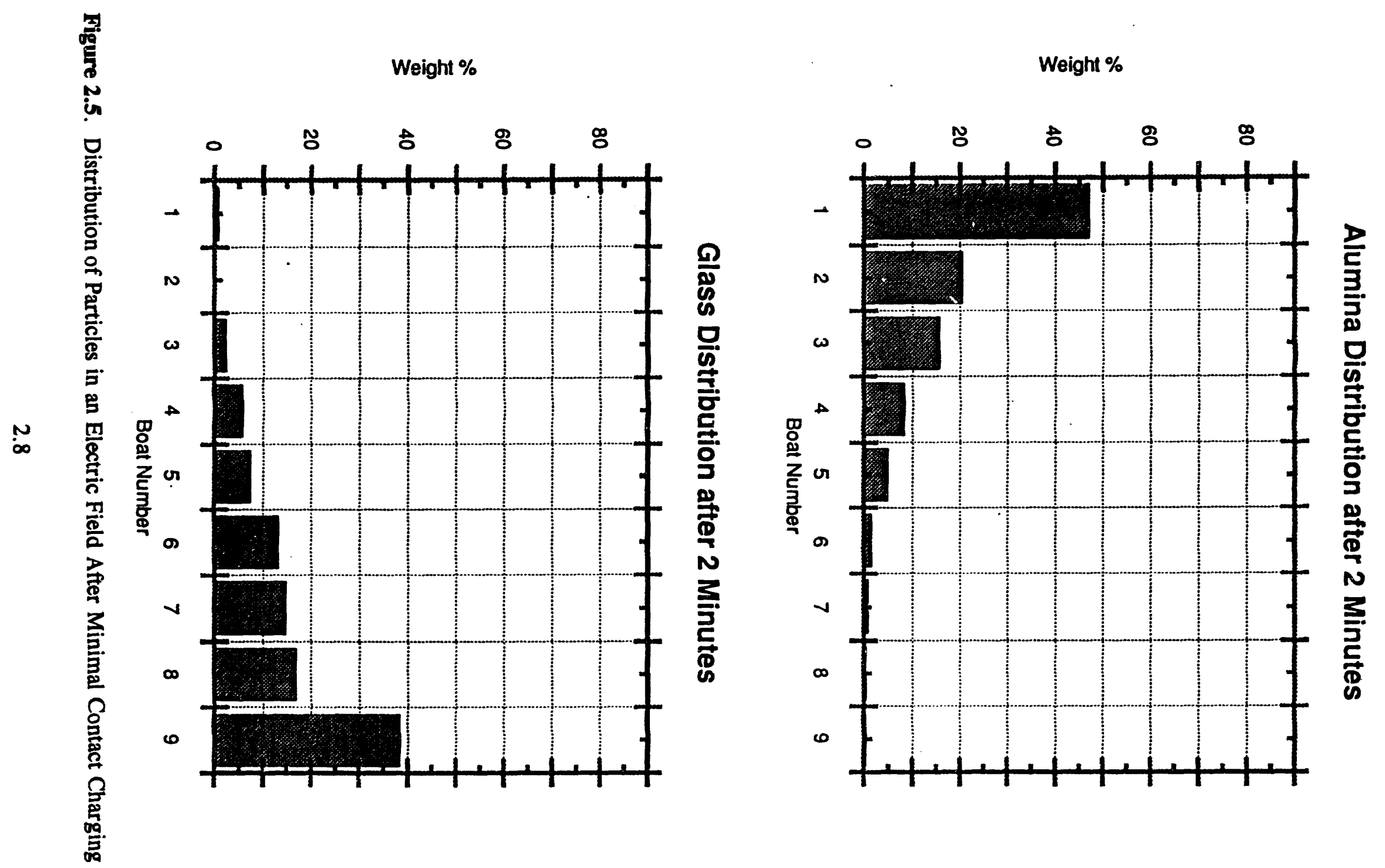

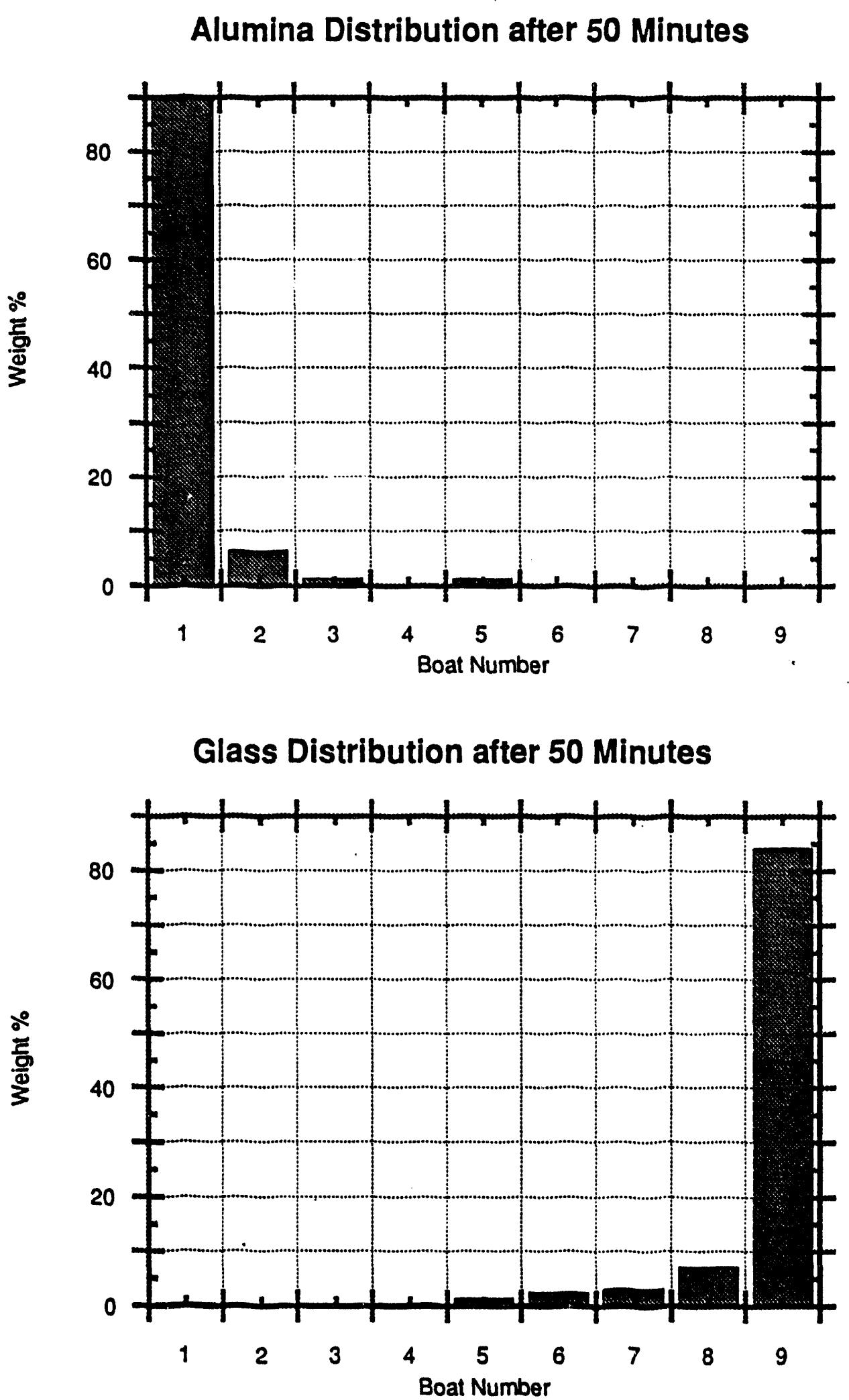

Figure 2.6. Particle Distribution in an Electric Field After Steady State Contact Charging 
Table 2.2. Charge-to-Mass Ratios Associated with Sample Boats in Figures 2.4, 2.5, and 2.6

\begin{tabular}{|c|c|c|c|c|c|c|}
\hline \multirow[b]{2}{*}{$\begin{array}{l}\text { Boat } \\
\text { Number }\end{array}$} & \multicolumn{2}{|c|}{$\begin{array}{l}\text { Sample Boat Position } \\
\text { Limits (from centerline of } \\
\text { deflectometer) }\end{array}$} & \multicolumn{2}{|c|}{$\begin{array}{l}\text { Corresponding } \mathrm{q} / \mathrm{m} \\
\text { Range for Alumina }\end{array}$} & \multicolumn{2}{|c|}{$\begin{array}{l}\text { Corresponding } \mathrm{q} / \mathrm{m} \\
\text { Range for Glass }\end{array}$} \\
\hline & 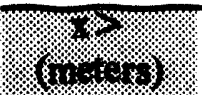 & $\begin{array}{c}\mathrm{x}< \\
\text { (meters) }\end{array}$ & 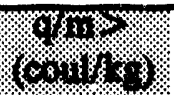 & $\begin{array}{c}\mathrm{q} / \mathrm{m}< \\
(\mathrm{coul} / \mathrm{kg})\end{array}$ & 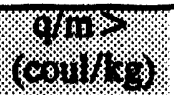 & $\begin{array}{c}\mathrm{q} / \mathrm{m}< \\
(\mathrm{coul} / \mathrm{kg})\end{array}$ \\
\hline 1 & \% & -0.080899 & 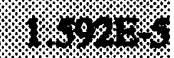 & $->+\infty(n)$ & $154 \cdot 54$ & $->+\infty(n)$ \\
\hline 2 & 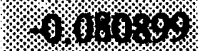 & -0.057785 & $1 \% 88.4$. & $1.592 \mathrm{E}-5$ & 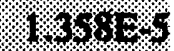 & $1.586 \mathrm{E}-5$ \\
\hline 3 & 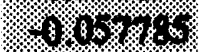 & -0.034671 & $x_{0}=3$ & $1.202 \mathrm{E}-5$ & 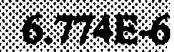 & $1.358 \mathrm{E}-5$ \\
\hline 4 & $8088_{5} \% 3$ & -0.011557 & $4 \gamma_{3}=1 \%$ & $7.204 \mathrm{E}-6$ & 174156 & $6.774 \mathrm{E}-6$ \\
\hline 5 & 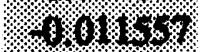 & +0.01157 & 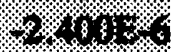 & $2.400 \mathrm{E}-6$ & $2261 \%$ & $2.261 \mathrm{E}-6$ \\
\hline 6 & $\% 800016 \%$ & +0.034671 & $1728 \%=0$ & $-2.400 E-6$ & $6.6 \% 4 \%$ & $-2.261 \mathrm{E}-6$ \\
\hline 7 & $10008 \% 3 \%$ & +0.057785 & $1.28018 \%$ & $-7.204 E-6$ & $1.368 \div 2 \%$ & $-6.774 E-6$ \\
\hline 8 & $18808 \times 866$ & +0.080899 & $145080 \%$ & $-1.202 E-5$ & $11.856 \mathrm{R}$ & $-1.358 E-5$ \\
\hline 9 & 0.000 .8309 & +0.10403 & 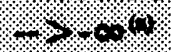 & $-1.592 E-5$ & 4.40 .1 & $-1.586 E-5$ \\
\hline
\end{tabular}

(a) Particles striking plates are assumed to be collected in outside sample boats ( 1 or 9 ).

separation (hence charging) exhibited by the alumina-glass pair was one reason for selecting that pair as the first to be tested in the heat exchanger. Other pairs of materials showed similar but generally less "clean" separation profiles with operating conditions shown in Table 2.1.

To verify that charging occurred primarily by particle-particle collisions rather than particle-wall collisions, we tested a bipolar charging fluidized glass-magnesia mix for net charge by running a quantity into a Faraday cup and measuring the total charge with an electrometer. Net charge on the mix was $1.0 \times 10^{-8}$ Coulomb $/ \mathrm{kg}$. (We expect that alumina and glass mixtures would give similar values.) For comparison, most glass particles from an $\mathrm{Al}_{2} \mathrm{O}_{3}$ glass mix achieved a negative charge and most $\mathrm{Al}_{2} \mathrm{O}_{3}$ particles achieved a positive charge exceeding $1.5 \times 10^{-5} \mathrm{C} / \mathrm{kg}$. The near neutrality of the mix suggests that particles acquire their charges from the other species and not from the walls.

Although Teflon paired with any of the other materials showed excellent charging, the screenable Teflon particle sizes were not a good fluidizing match with the other materials. Fluidization problems with Tefion increased as temperatures increased toward $180^{\circ} \mathrm{C}$. Thus, Teflon is considered by us to be a poor choice for simultaneocs fluidization with other materials. All three other pairs of materials (alumina-glass, magnesia-glass, and alumina-magnesia) were considered good candidates for future study. Alumina and glass were readily available in the right particle size range, with little sieving required. Thus, that pair was selected for initial testing in the fluidized bed heat exchanger.

\subsubsection{Fluidized Bed Heat Exchanger Tests}

Prior to adding particles to the bed, two air-only runs were completed. These runs showed the expected temperature rise as gas flowed through the heated tube bank. They also confirmed that the 
data acquisition and data reduction procedures were correct. An applied electric field of $20 \mathrm{kV} \mathrm{p}-\mathrm{p}$ produced no effects at $10 \mathrm{~Hz}, 20 \mathrm{~Hz}$, or $40 \mathrm{~Hz}$. Lack of an effect is consistent with our original conjectures.

Several runs were made on the heat exchanger at relatively low voltages (5 to $7 \mathrm{kV} \mathrm{p}-\mathrm{p}$ ) using the glass-alumina particle pair. The low voltages minimized chances of arcing in the bed and consequent damage to the instrumentation. These : Jw voltages produced no measurable effect on the heat transfer in the bed. No arcing was observed. No observable effects at these fleld strengths was also consistent with our theory.

Observable effects at $10 \mathrm{~Hz}$ started when the voltages were increased to $20 \mathrm{kV} \mathrm{p}-\mathrm{p}$. Arcing was suppressed using the pure alumina-glass particles and $10 \mathrm{meg}-\mathrm{ohm}$ ballast resistors. The initial result was a puzzling yet reproducible temperature drop from the bottom to the top of the bed. Since air is admitted at the bottom of the bed and flows up through five rows of heaters before exiting, it is logical to assume that its temperature would rise. This anomaly prompted us to re-calibrate all the instruments, retrace instrument lines, and do manual checks on all the data reduction formulas. No signifcant problems or errors were found.

The conclusion was that heat transport within the fluidized bed occurs so readily that heat losses to the walls could not be neglected. Hence, the system could not be adequately characterized by the temperatures of various layers. This led us to a new configuration of the gas phase temperature sensors for measurements with particles present. Gas phase temperature sensors were placed in each of the four major gaps between the center rod (column 3, level 3 in the $5 \times 5$ array) and its eight nearest neighbors, as shown in Figure 2.7. This allows us to determine an average temperature of the rod surroundings, independent of whether or not the flow is one-dimensional. Furthermore, we can take heat transfer data as soon as the center rod's skin and immediate surroundings reach a quasi-steady state, without waiting for the entire system to do so.

Two (out of six total) runs for the alumina-glass pair are summarized in Figures 2.8 to 2.10 . The relevant operating parameters are shown in Table 2.3. Figure 2.7 shows the temperature measurement locations. It also shows an indexing pattern to explain the "row" and "column" designations in Figure 2.10. Figures 2.8 and 2.9 show representative temperature data. These particular runs focused on the center tube in the bed. RTDs were rearranged as described in the preceding paragraph to give 4 gas/particle temperature values around that tube. As shown in Figure 2.7, the center tube also has an RTD to measure its skin temperature.

The run summarized in Figure 2.8 used a $20 \mathrm{kV}$ p-p AC electric field in all cases except the $0 \mathrm{~Hz}$ case, which had zero field strength. The applied field changed from 0 tn $20 \mathrm{kV} p-p$ at 10,20 , and 40 $\mathrm{Hz}$ in turn. The figure shows that system temperatures did indeed change when the field was applied. The greatest effect occurred at $10 \mathrm{~Hz}$. Unfortunately, the effect was to increase skin temperatures $T_{\text {, }}$ more than gas temperatures $T_{z}$, so that the net effect was a decrease in the heat transfer coefficients. Figure 2.9 is a separate run where initial operating conditions were set to match as closely as possible those that generated Figure 2.8. The data at zero field and those at $10 \mathrm{~Hz}$ show good reproducibility. The run of Figure 2.8 had a $40 \mathrm{~Hz}$ exposure period, while that of Figure 2.9 had a $100 \mathrm{~Hz}$ exposure period, but we presume that reproducibility would have been similar at these frequencies. The DC data alternated between $+10 \mathrm{kV}$ and $-10 \mathrm{kV}$ at ten minute intervals. 


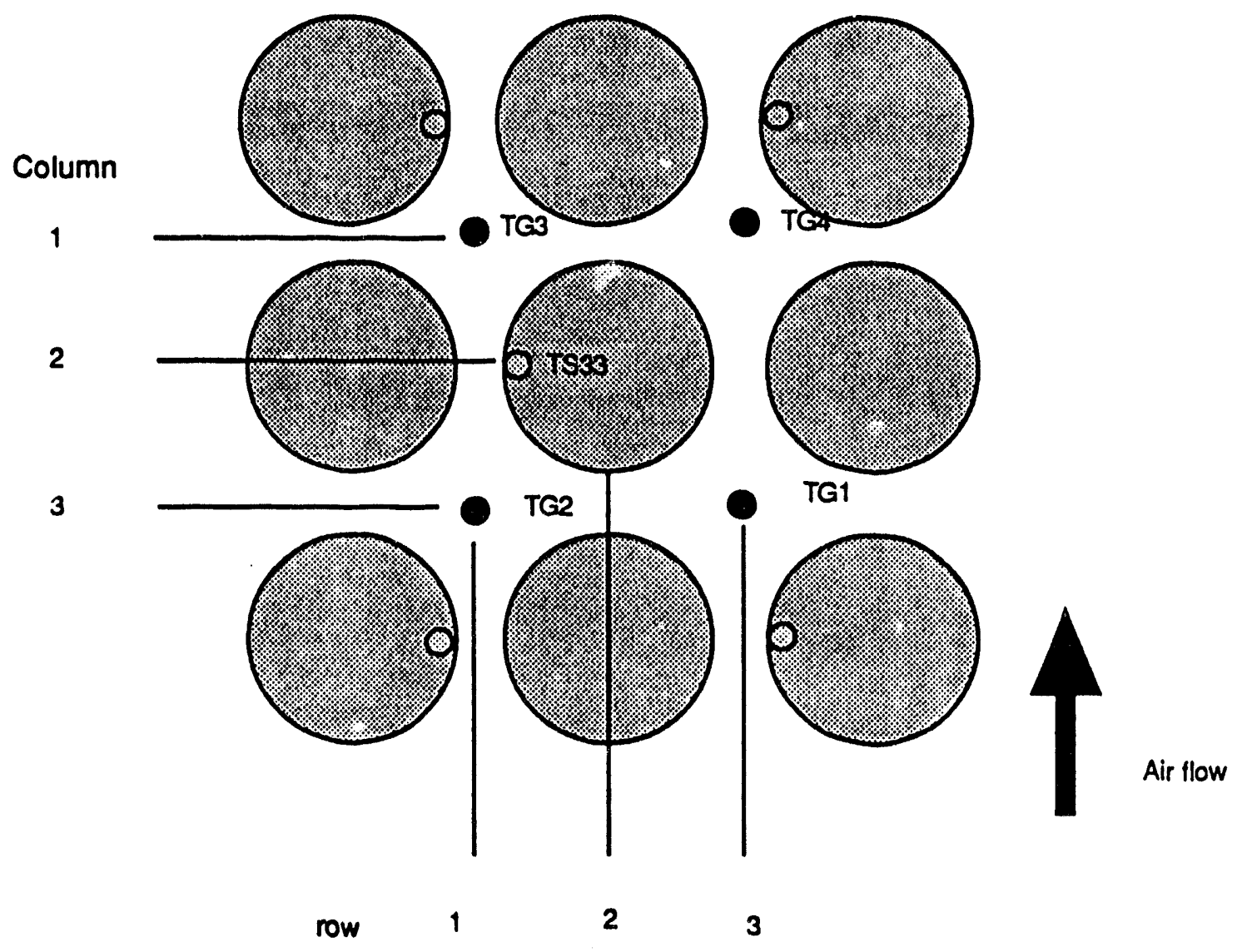

Key to $3 \times 3$ positional Temperature Plots

Figure 2.7. Central Tube and RTD Layout

Figure 2.10 shows the temperature profiles for the zero field, $10 \mathrm{~Hz}, 100 \mathrm{~Hz}$, and DC operation in a slightly different manner. Time marches from left to right, then top to bottom in the figure sequence. The row and column markers correspond to the indexing pattern shown in Figure 2.7. The four corners of the plotted figure are gas temperatures, while the center apex represents the tube skin temperature. These 3-dimensional views show the temperature gradients from tube to gas quite dramatically.

For the runs shown in Figures 2.9 and 2.10, the heat transfer coefficients for the $40 \mathrm{~Hz}$ and $100 \mathrm{~Hz}$ fields are negligibly different from the zero field case, as can also be seen in Table 2.3. This was not surprising to the investigators, who had predicted that the small amplitude of the charged particle oscillations at these frequencies would cause the electric fields to be ineffective in influencing heat transfer. It was concluded later, of course, that the decline in effects with increasing frequency above $20 \mathrm{~Hz}$ was due to the decline in the ability of the field to make the bed more rigid. The effect of the DC field on reducing the heat transfer (i.e., increasing the tube-to-gas temperature gradient) was expected for both $+D C$ and $-D C$. But clearly, there was no significant inhibition at $-10 \mathrm{kV}$. Since glass charges negatively relative to alumina, we expected it to cling to and insulate the grounded tube when the adjacent 


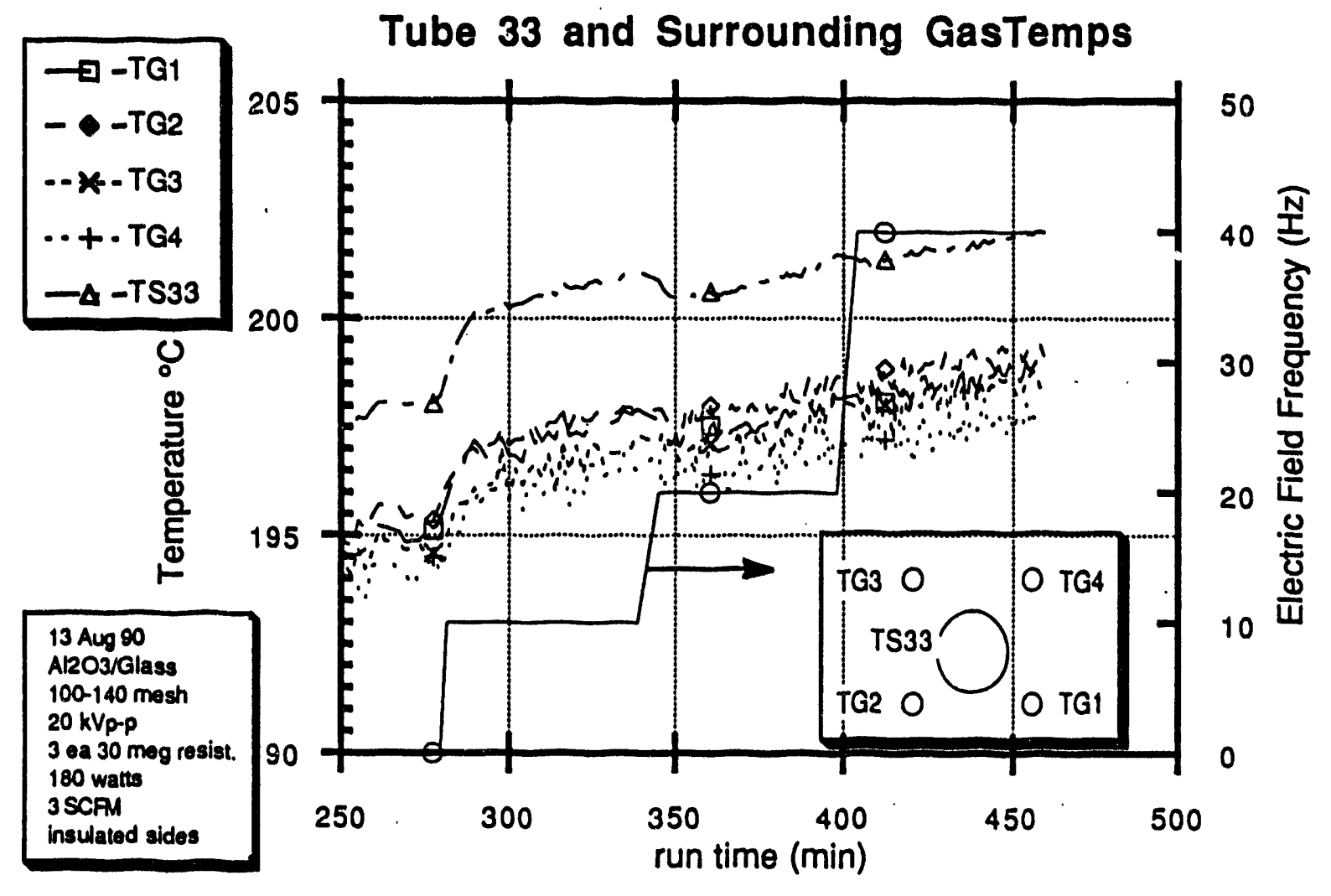

Figure 2.8. Temperature Profiles Around Center Tube

rods are at $-10 \mathrm{kV}$. This apparently did not happen. We speculate now that the glass particles lose charge rapidly on contact with the aluminum rods. On the other hand, when the field was switched to $+10 \mathrm{kV} \mathrm{DC}$, the alumina particles did cling to the center rod and formed an insulating barrier. The effect was to decrease heat transfer coefficients for the tube by a factor of two. This difference in the thermal shielding effects of glass and alumina particles is opposite to that implied by the difference in their thermal conductivities alone.

\subsubsection{Charge Spectrum Analysis}

Measurement and analysis of the charge spectrum is simplified somewhat by the fairly narrow size range of particles of each type that were fluidized and also by the fact that electrical forces can be made of the same order of magnitude as gravitational forces for particles in the selected size range. The charge-to-mass ratio is deduced from the magnitude of the horizontal displacement produced by an electric field while the particle is also subject to a gravitationally produced vertical displacement, as in the apparatus shown in Figure 2.3.

The position of the particle after exiting from the sample valve (entering the particle addition tube) obeys Newton's Law in the form: 


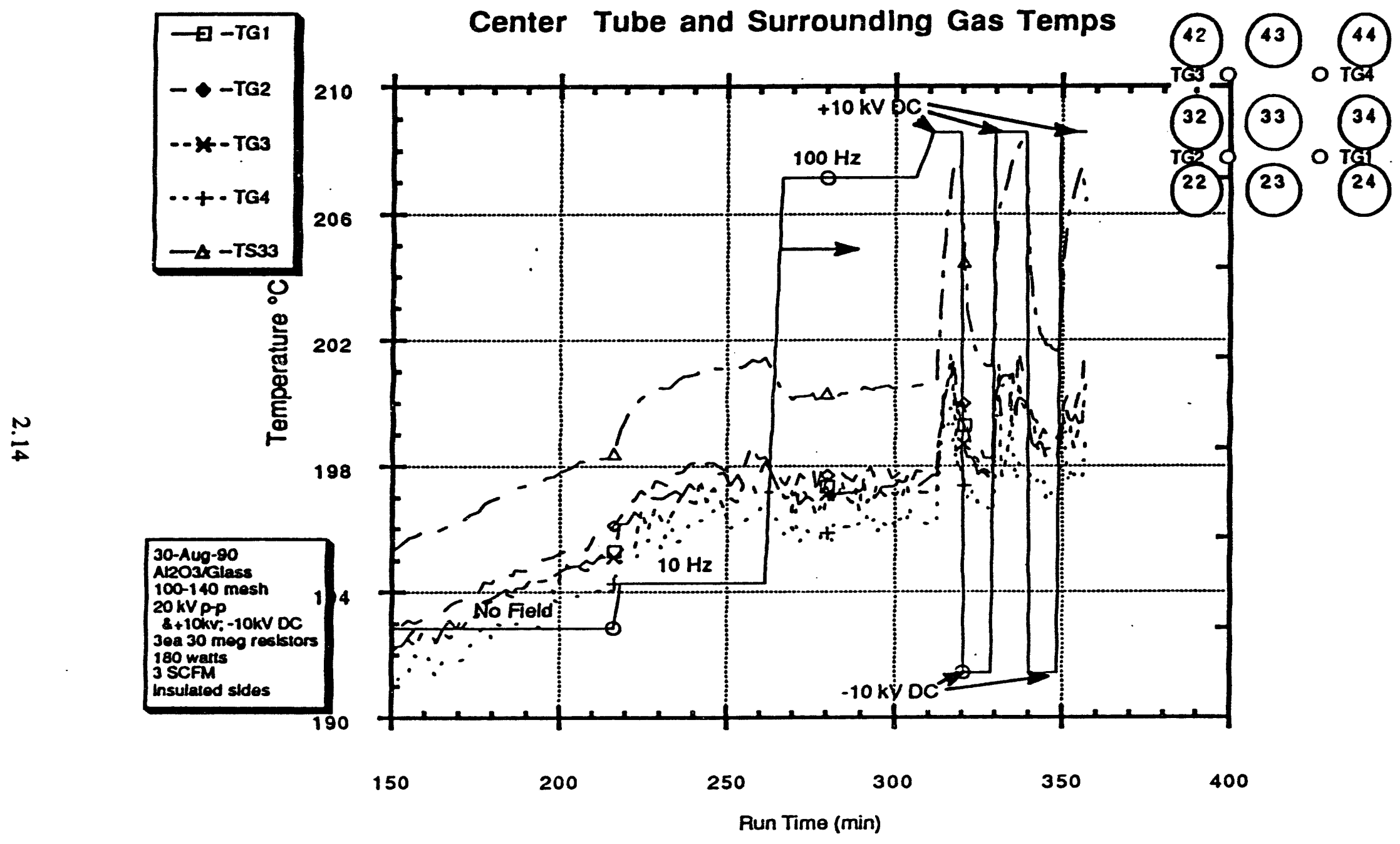

Figure 2.9. Temperature Profiles for AC and DC Operation 


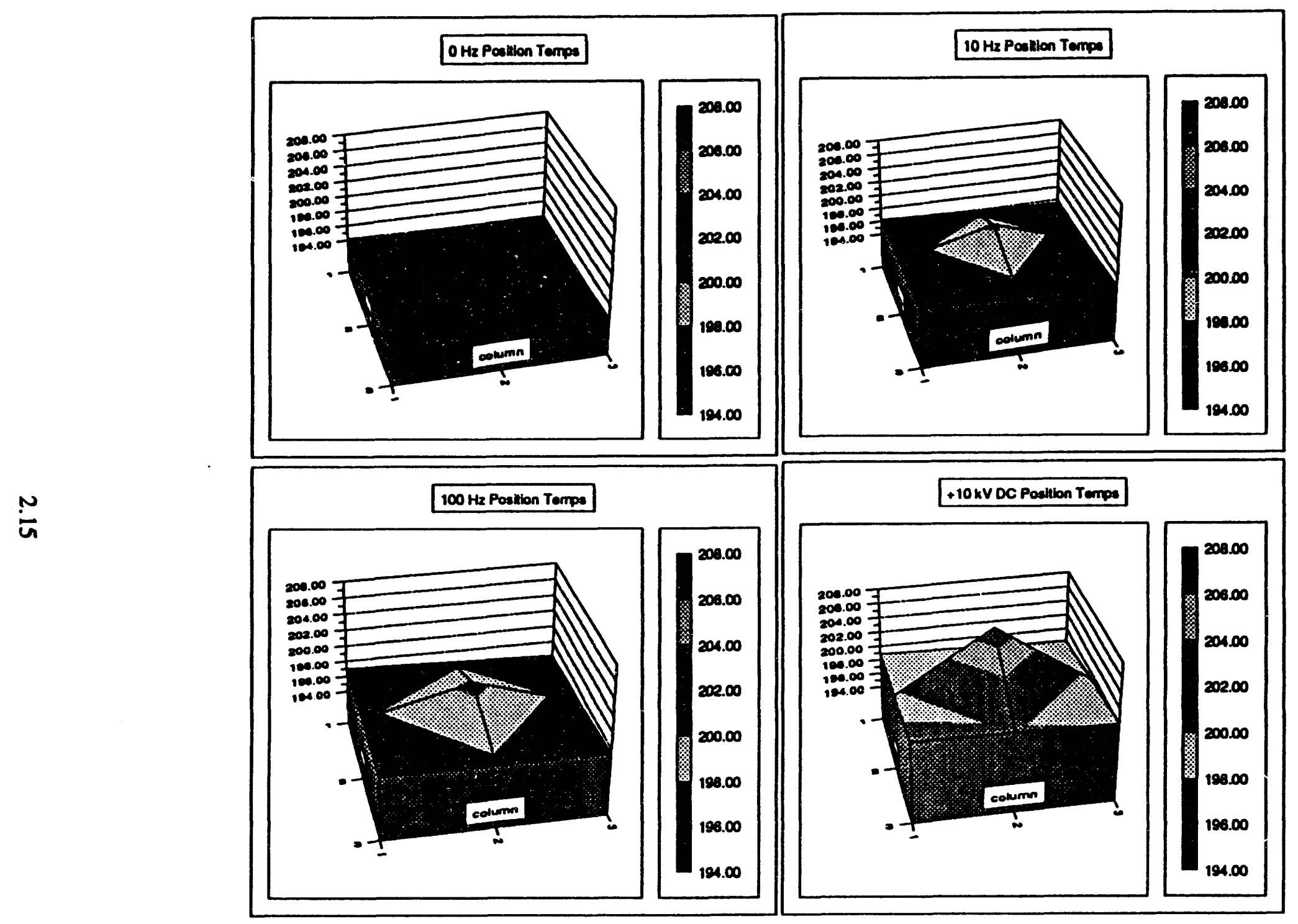

Figure 2.10a. Temperature Gradients with No Field, AC, then DC Field Applied 

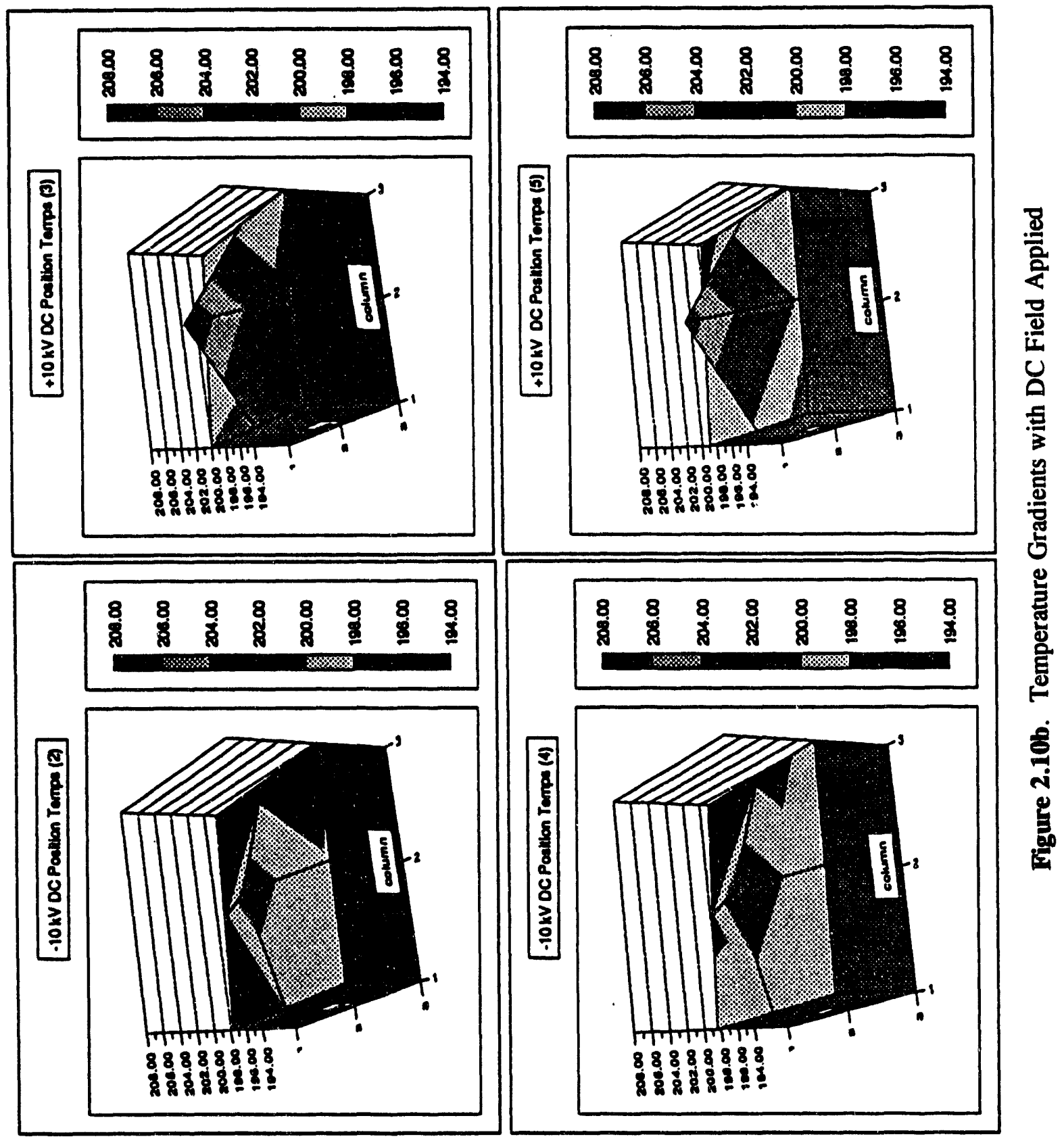
Table 2.3. Input Data and Results of Heat Transfer Analyses

Experimental and Calculated Heat Transfer Information

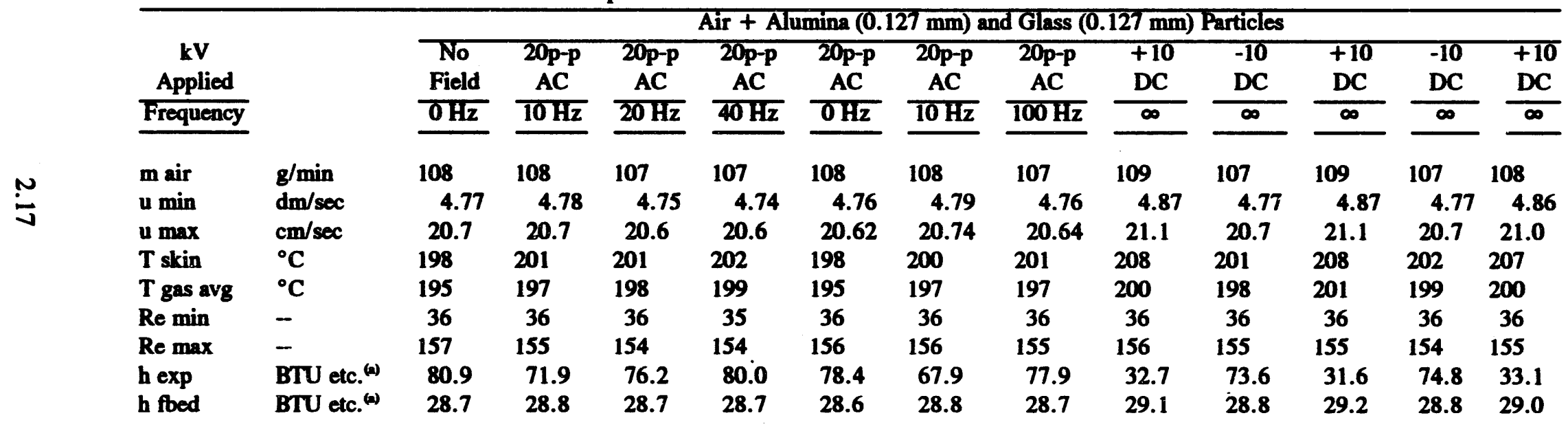

(a) BTU etc. $=\mathrm{BTU} / \mathrm{hr}-\mathrm{ft} \wedge 2-{ }^{\circ} \mathrm{F}$... to convert to $\mathrm{W} / \mathrm{m} \wedge 2-^{\circ} \mathrm{K}$ multiply by 5.67 . 


$$
m_{p} d^{2} r / d t^{2}=m_{p} g+q E+F_{D}
$$

where $m_{p}=$ particle mass

$d^{2} r / d t^{2}=$ vector particle acceleration

$\mathbf{g}$ is the acceleration of gravity

$q$ is the particle charge

$\mathbf{E}$ is the electric field vector

$F_{D}$ is the air drag force which acts in the opposite direction to the instantaneous velocity.

The applied electric field in the deflectometer is primarily horizontal, while the gravitational field is vertical. The drag force has the form:

$$
\mathbf{F}_{\mathrm{D}}=-\mathrm{f}\left(\mathrm{r}_{\mathrm{p}}, \mu, \mathrm{V}\right) \mathbf{V}
$$

where $\mathbf{V}$ is the instantaneous velocity

$r_{p}$ is the particle radius

$\mu$ is the air viscosity.

Thus, the ratio of horizontal to vertical deflections of a particle travelling at terminal velocity with a uniform horizontal electric field would be:

\section{$q E / m_{p} g$}

and hence would give values of $q / m_{p}$ directly.

We deduce values of $q / m_{p}$ for the deflectometer tests by integrating Equation 1 for the mean particle size of each type used and for a range of $q / \mathrm{m}_{\mathrm{p}}$ values. Table 2.2 is really a table of terminal horizontal displacement vs $\mathrm{q} / \mathrm{m}_{\mathrm{p}}$. It gives for each particle type a $\mathrm{q} / \mathrm{m}_{\mathrm{p}}$ range for the particles that land in each sample boat. The drag force expression is based on a well-founded empirical correlation between Galileo number and terminal Reynolds number for falling particles (Davidson and Harrison 1971, p. 51). Results are somewhat insensitive to the drag model if the particle is travelling at near terminal velocity during most of its settling period. The electric field was approximated by the potential difference divided by the deflectometer plate separation at each height in the region between plates. Above the upper edges of the plates, the field was approximated as that from two parallel wires located at the plate edges.

\subsubsection{Heat Transfer Analysis}

One way to analyze results from our experiments is to compare the measured heat transfer coefficients with those from accepted engineering correlations. Table 2.3 summarizes those calculations for two different runs using alumina-glass. (A single run can examine several frequencies). Our experimental heat transfer coefficient $h_{\text {oxp }}$ is evaluated from 


$$
Q_{\text {total }}=h_{\text {oxp }} A\left(T_{s}-T_{\text {avg }}\right)
$$

where $Q_{\text {total }}=$ measured electrical heat input to the tube (or tubes)

$\mathrm{T}_{\mathrm{s}}=$ surface temperature

$T_{\mathrm{avg}}=$ average gas temperature

$Q_{\text {total }}$ is measured with watt meters on the individual rows of heaters. $T_{\mathrm{g}}$ and $T_{\text {avg }}$ are known from the calibrated RTD readings. Since $A$ is simply the tube surface area available for heat transfer, Equation 3 can be solved for numerical values of $h_{\text {exp }}$.

Accepted engineering heat transfer correlations are generally given in terms of dimensionless groups that include the Prandtl number Pr, Reynolds number Re, and Nusselt number Nu, defined by:

$$
\operatorname{Pr}=C_{p} \mu / k
$$

$$
\text { where } \begin{aligned}
\mathrm{C}_{\mathrm{p}} & =\text { heat capacity }\left(\mathrm{cal} / \mathrm{g}^{\circ} \mathrm{C}\right) \\
\mu & =\text { viscosity }(\mathrm{g} / \mathrm{cm}-\mathrm{sec}) \\
\mathrm{K} & =\text { thermal conductivity }\left(\mathrm{cal} / \mathrm{cm} 2-\sec -\left[{ }^{\circ} \mathrm{K} / \mathrm{cm}\right]\right)
\end{aligned}
$$

and

$$
\operatorname{Re}=\operatorname{dup} / \mu
$$

where $\mathbf{d}=$ diameter $(\mathrm{cm})$ [tube or particle diameter depending on the correlation]

$\mathrm{u}=$ velocity $(\mathrm{cm} / \mathrm{sec})$

$\rho=$ fluid density $\left(\mathrm{g} / \mathrm{cm}^{3}\right)$

and

$$
\mathrm{Nu}=\mathrm{h}_{\mathrm{c}} \mathrm{d} / \mathbf{k}
$$

where $h_{c}=$ convective heat transfer coefficient

In applying correlations with dimensionless numbers, it is necessary to be specific in choices of distance or velocity parameters. For example, in heat exchanger tube arrays or in the rod arrays of this experiment, the flow velocity parameter $u$ which can be inserted into the Reynolds number is bounded by $u_{0} \leq u \leq u_{\max }$, where 


$$
\begin{aligned}
& u_{0}=u_{\min }=\text { superficial velocity based on tube-free area } \\
& u_{\max }=\text { stream velocity based on minimum open area. }
\end{aligned}
$$

For fluid bed heat transfer, a correlation from Kunii and Levenspiel (1969, p. 272) is:

$$
h_{\text {fbod }} d_{\mathrm{t}} / k=0.66 \operatorname{Pr}^{0.3}\left[\operatorname{Re}_{\mathrm{t}}\left(\rho_{\mathrm{g}} / \rho_{\mathrm{g}}\right)\left(\left(1-\epsilon_{\mathrm{f}}\right) / \epsilon_{\mathrm{f}}\right)\right]^{0.44} \text { for } \operatorname{Re}<2000
$$

where $\operatorname{Re}_{\mathrm{q}}=\mathrm{Re}$ based on tube outside diameter and superficial velocity

$h_{\text {fbed }}=$ heat transfer coefficient from a horizontal tube to the fluidized bed

$\epsilon_{\mathrm{f}}=$ void fraction in bed at fluidizing conditions

The correlation applies specifically to immersed horizontal tubes in a fluidized bed. The authors cite broad validity, including data from large-scale fluidized beds.

Kunii and Levenspiel also cite some work which shows that $h_{f b e d}$ is a strong function of superficial velocity at low velocities. They present experimental $h$ values that go through a maximum before leveling off at high velocities. Heat transfer coefficients in fluidized beds increase with increasing velocity at low velocities, showing the effects of increasing mass motion and erosion of boundary layers. Heat transfer peaks at some value $h_{\max }$, then declines with increasing velocity thereafter because of the increasing void fraction. A correlation given by Davidson and Harrison (1971, p. 516) gives the maximum Nusselt number for a bank of tubes aligned in the flow direction as:

$$
(\mathrm{Nu})_{\max }=\left(\mathrm{h} \mathrm{d} \mathrm{d}_{\mathrm{p}} / \mathrm{k}_{\mathrm{f}}\right)_{\max }=0.79(\mathrm{Ar})^{0.22}\left(1-\mathrm{D}_{\mathrm{R}} / \mathrm{S}_{\mathrm{h}}\right)^{0.25}
$$

where $d_{p}=$ particle diameter

$D_{R}=$ tube diameter

$S_{h}=$ pitch of the array in the horizontal direction

and $\mathrm{Ar}$ is the Archimedes number:

$$
\operatorname{Ar}=g d_{p}^{3} \rho_{f}\left(\rho_{p}-\rho_{f}\right) / \mu^{3}
$$

where $\rho_{\mathrm{f}}=$ fluid density

$\rho_{\mathrm{p}}=$ particle density

$\mathbf{g}=$ acceleration of gravity 
Applying this correlation to our fluidized bed conditions gave as the maximum heat transfer coefficient

$$
h_{\max }=70.1 \mathrm{Btu} / \mathrm{ft}^{2-} \mathrm{hr}-{ }^{\circ} \mathrm{F}
$$

Other results from our experiments are shown in Table 2.3. They show what was tentatively interpreted as a potentially beneficial effect on heat transfer from the presence of the charge on the particles, even without an applied electric field. Our experimental heat transfer coefficients with no electrical field applied appeared consistently higher than predicted by Equation 4 . They also exceeded the peak values predicted by Equation 5. This seemed to indicate that higher heat transfer coefficients were being achieved from the mere presence of bipolar charge. Such an enhancement would be signifcant for both its theoretical implications and its economic impact. It suggested that the dominant mechanism for heat transfer enhancement is improved particle-to-wall thermal contact, and not increased sensible heat transport, as we believed earlier. It further implied an opportunity for improved heat recovery by a safer, more passive, and less costly system than the high voltage AC arrangement we had originally envisioned. Because of its importance and the difficulty of accurate measurements (not unlike calorimetric tests of cold fusion), this result was regarded as needing further verification. Section 3 describes the tests we performed to verify or refute this finding. As will be seen in Section 3, accounting for axial heat flow in the calculation of the heat transfer coefficient from the experimental data removed most of the anomaly. We strongly suspect that the remaining variability of experimental heat transfer coefficients as compared with standard correlations is related to particle roundness.

Heat transfer information summarized in Table 2.3 also shows a heat transfer inhibition (as we had predicted) for high voltage DC applied between heater rods immersed in a bipolar-charging two-material fluidized bed. Unexpectedly, however, there was an observed dependence on polarity for the alumina-glass combination studied. This can be reconciled if one hypothesizes that glass loses charge rapidly on contact with the aluminum rods. Glass had been found in our charge measurements (deflectometer tests) to charge negatively when fluidized with $\mathrm{Al}_{2} \mathrm{O}_{3}$. When a particular electrode (heater rod) was at positive relative potential (and hence should coat with glass), heat transfer inhibition was small. When the electrode was negative (and hence should coat with $\mathrm{Al}_{2} \mathrm{O}_{3}$ ), a strong heat transfer inhibition occurred. This is consistent with the glass particles forming a less permanent layer than the $\mathrm{Al}_{2} \mathrm{O}_{3}$, because the glass particles lose charge.

AC field tests in this alumina-glass bed showed a heat transfer inhibition, contrary to the enhancement that was expected. Maximum inhibition effect occurs at 10-20 Hz. Very little inhibition occurs at $100 \mathrm{~Hz}$. We hypothesize that inhibition occurs because:

1. at the low void fraction conditions of the experiment, the bed particles experience strong mechanical drag which resists the counterflow of positive and negative particles;

2. the glass particles may lose charge too quickly during contact with the heater rod electrodes, so that they are not pushed away when the fleld changes sign, but instead build up an insulating layer;

3) the low frequency electric field, like DC, makes the bed more rigid and thus inhibits sensible heat transport. 


\subsection{Clarifying Investigations and Inferences}

\subsection{Particle Charging}

Our experimental data on electrical charging show that resistive particles of two dissimilar materials fluidized together will achieve high and opposite electrical charges, and that the time scale for charging to occur is a few minutes. The measurements reported here for the glass-alumina combination show that a major portion of the particles reached a $|\mathrm{q} / \mathrm{m}|$ value of $1.8 \times 10^{-5} \mathrm{C} / \mathrm{kg}$, which implies a surface field strength equal to $5 \%$ of the electrical breakdown field strength in air. For the very resistive alumina, it seems likely that collision processes produce at any instant a non-uniform charge distribution on the surface, perhaps with many patches having a charge, and resulting in a field strength approaching the electrical breakdown value in air. This non-uniform charge could result in both rolling contacts and improved thermal contact from attractive forces during particle-rod collisions, thereby enhancing heat transfer. Additional deflectometer tests, with different field strengths or plate spacings, confirmed the high levels of species-specific charging in all pairwise combinations of glass, $\mathrm{MgO}$, and $\mathrm{Al}_{2} \mathrm{O}_{3}$. Figure 3.1 shows one of the clearest spatial separations and species-specific $\mathrm{q} / \mathrm{m}$ distributions obtained in these higher resolution tests, that for $\mathrm{Al}_{2} \mathrm{O}_{3}$ and glass.

Charging measurements of the type made in this study could be used with a model for collision rate and collision contact area to further study the charging process in contacts of resistive surfaces. The charging measurements could be further analyzed to determine which physical parameters (resistivity, density of surface states, band gap energy, ionization energy, etc) correlate with the attained charge. This could be part of a fundamental study of the physics of resistive surfaces, but it was beyond the resources of this project.

The high fleld strengths that occur at the surfaces of the fluidized particles (sized in the tenths of a millimeter) should be useful for removal of fine particulates (sized in the tenths of a micron) from the fluidizing gas stream, using either the natural charge distribution or indyced dipole moments of the particulates. This will be considered for possible future study and application to gas cleanup.

\subsection{Charge Transport Phenomena}

The electrical arcing problems encountered when alternating potentials are applied between electrodes immersed in the fluidized bed provide clues to the physical phenomena involved. When arcing occurred, it appeared after a period of time on the order of bed charging time. This suggests that free charges produced by repeated contacts may be involved in arcing, rather than intrinsic charge carriers (electrons or holes). The presence of titanium impurities in alumina was shown to increase arcing problems. The nature of these charge transport processes (role of impurities, surface or volumetric charge motion, etc. ) can be investigated by varying the material and size, the applied voltage, and the fluidization time, but we did not have the resources to do this in the present study. 


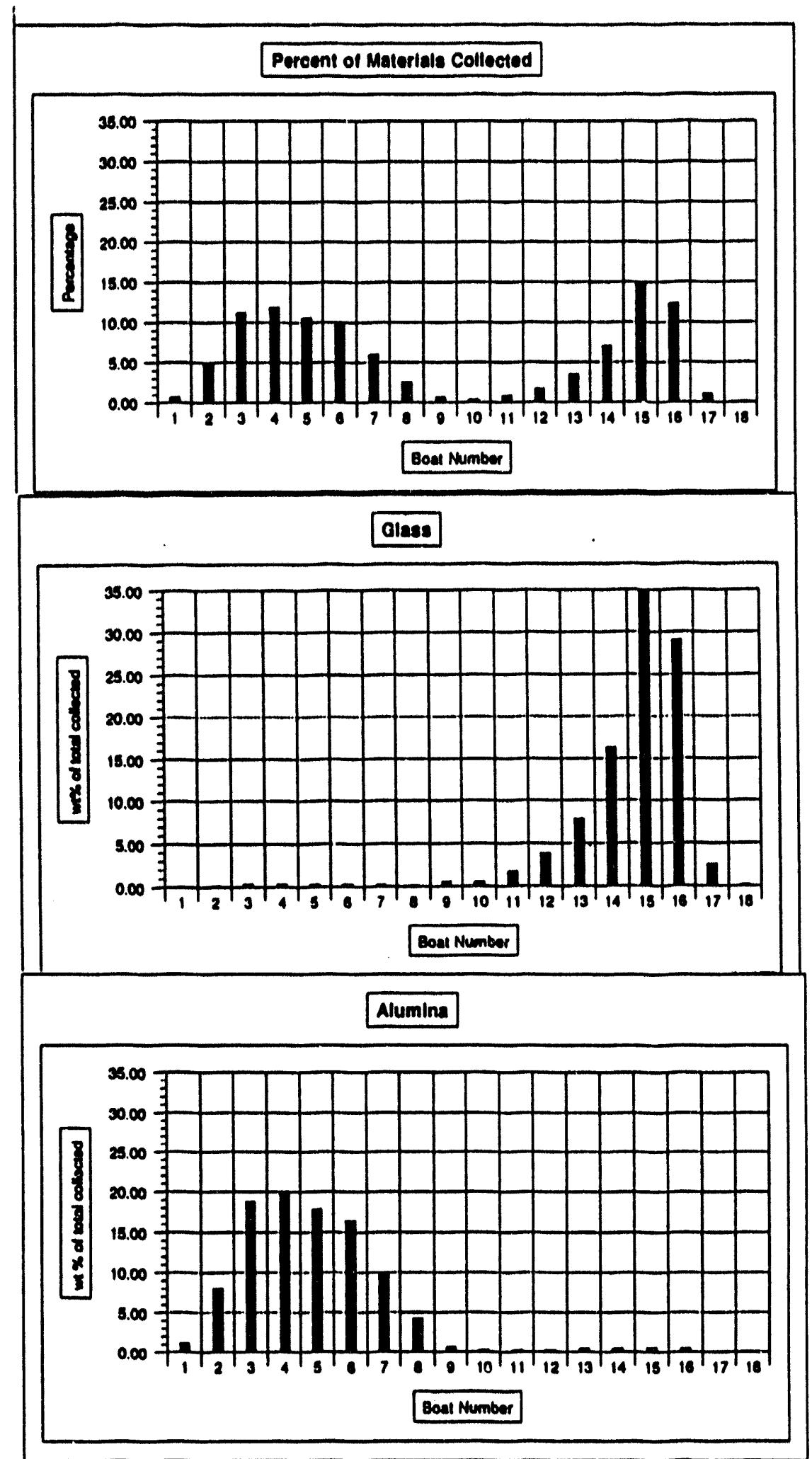

Figure 3.1. Higher Resolution Postfluidization Deflection Spectrum of $\mathrm{Al}_{2} \mathrm{O}_{3}$-Glass Particle Mix 


\subsection{Heat Transfer Phenomena}

To clear up anomalies previously discussed, we undertook a new round of experiments and data analysis. Measurements were taken for a total of 53 sets of bed materials, electric field strength, electric field frequency, superficial velocity, and fluidizing gas. The correlation of this rather massive amount of heat transfer data is incomplete, but salient results will be presented here. Table 3.1 summarizes the parameter variations.

\subsubsection{Axial Heat Flow Corrections}

A signiflcant change in the data analysis for this expanded now round of experiments was the application of an axial heat flow correction to the calculation of heat transfer coeficients. A program (HFIT )was written, which applied a fin heat transport calculation to account for end losses from the heater rod elements in the bed. This more sophisticated calculation to deduce the heat transfer coefficient gave results in agreement with standard fluidized bed correlations to within $\pm 25 \%$ for most zerofleld cases, for which the standard correlations should apply. Departures from standard correlation values were still notable for fluidized bed loadings of quartz only. The special behavior of quartz is discussed below.

\subsubsection{Electric Fleld Effects on Heat Transfer}

Variations associated with the applied electric fields were the same as found previously: compared with the case of no applied potential difference, there was typically strong heat transfer inhibition at zero frequency and at 10 and $20 \mathrm{~Hz}$, with weakening of the inhibition at $40 \mathrm{~Hz}$, for most fluidized solid bed loadings. A notable exception was that of quartz particles, which showed a heat transfer enhancement with an applied $20 \mathrm{kV}$ potential at $10 \mathrm{~Hz}$. This is in agreement with the results of Elsdon and Shearer (1977), who reported heat transfer enhancement in quartz fluidized beds with an applied AC field. Interestingly, this sole case from the literature under conditions comparable to ours describes what appears to be an exceptional case. We attribute the special behavior for quartz to the following combination of causes:

Table 3.1. Parameters Varied in Fluidized Bed Heat Transfer Experiments

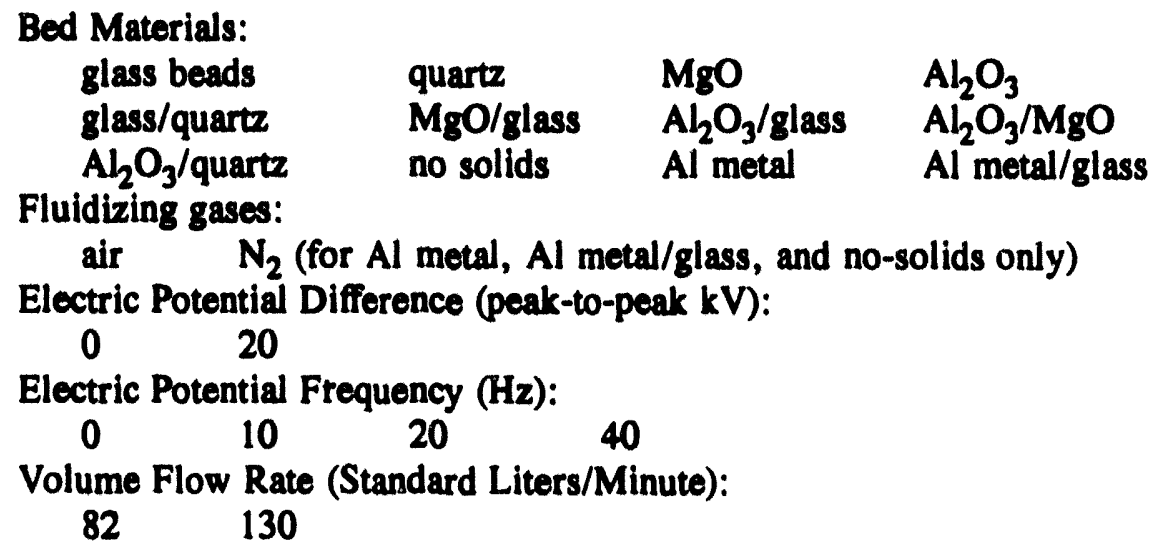


1. the quartz particles were significantly non-spherical, so they made poor thermal contact with the heater rods in the absence of an applied potential difference;

2. quartz is known to exhibit different piezoelectric charges on different crystalline faces, so an applied field is especially effective in improving the thermal contact by rolling the particle around during its contact with the surface of the heater rod.

Glass, by contrast, shows strong inhibition of heat transfer under the influence of an applied field. The glass particles used in the tests were nearly spherical glass beads, as can be seen in micrographs. Roundness statistics for the glass and the quartz used appear in Table 3.2. The roundness is the ratio $(S / D)_{\text {aphoro }} /(S / D)_{\text {particle, }}$ where $S$ and $D$ are surface area and diameter, respectively, and $D_{\text {partiolo }}$ is a weighted average transverse dimension for the particle. The roundness statistics are determined by computer processing of micrograph scans.

The heat transfer characteristics of fluidized beds of glass beads and of quartz are shown in Table 3.3. While quartz shows a positive effect on heat transfer in the presence of an oscillatory electric field, it is not of economic interest because it exhibits an anomalously low heat transfer coefficient. We attribute this to the departure from roundness of its particles and to its fairly low thermal conductivity. Neither of these properties appear in the most common standard correlations.

The general failure of the heat transfer enhancement predicted by the investigators can be attributed to the predominance of the electric fleld's bed stabilization effects over the effects from local charged particle motion enhancement (with resulting sensible heat transfer enhancement) which were emphasized in the investigators' model. Electric field stabilization of dielectric beds was ciscussed by

Table 3.2. Roundness Characteristics of Glass Beads and Quartz Particles Used in Fluidized Bed Heat Transfer Tests

\begin{tabular}{|c|c|c|}
\hline Material & Diameter ( $\mu \mathrm{m})$ & Roundness \\
\hline $\begin{array}{l}\text { Glass beads } \\
\text { Quartz }\end{array}$ & $\begin{array}{l}107 \pm 8 \\
177 \pm 22\end{array}$ & $\begin{array}{l}0.85 \pm 0.01 \\
0.53 \pm 0.13\end{array}$ \\
\hline
\end{tabular}

Table 3.3. Heat Transfer Coefficients $h\left(B T U / \mathrm{tt}^{2}-\mathrm{hr}-{ }^{\circ} \mathrm{F}\right)$ of Glass Beads and Quartz Particles Used in Fluidized Bed Heat Transfer Tests at Varying Applied Potentials V(kV, Peak-to-Peak) and

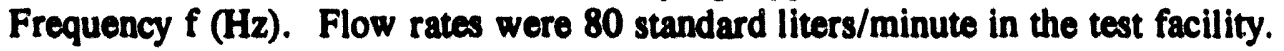

\begin{tabular}{|c|c|c|c|}
\hline Material & $V=0$ & $V=20, f=10$ & $V=20, f=40$ \\
\hline $\begin{array}{l}\text { Glass beads } \\
\text { Quartz }\end{array}$ & $\begin{array}{l}77 \\
22\end{array}$ & $\begin{array}{l}32 \\
28\end{array}$ & $\begin{array}{l}64 \\
24\end{array}$ \\
\hline
\end{tabular}


Colver (1976). Bed stabilization seems to occur in a charged bed as well. In our bipolar charged bed, the onset of bed bubbling was visibly shifted to higher flow rates by the presence of the electric field, and the intensity of bubbling at a given flow rate appeared to be lower than with no applied fleld. Presumably, the agitation which produces high heat transfer rates in a fluidized bed is suppressed by the electric field's stabilizing effects.

\subsubsection{Zero Field Efiects from Bipolar Charging}

First round tests without axial heat flow corrections in their analysis led us to believe that a positive heat transfer effect was occurring, because the heat transfer coefficients were somewhat higher than those given by standard correlations for comparable single substances. However, accounting for axial heat flow brought the deduced heat transfer coefficients into line with published correlations. Nevertheless, there are still some ambiguities in applying standard fluidized bed heat transfer correlations to beds of mixed materials. To test for a positive effect from a particle mix which charges, we compared our experimental heat transfer coefficients for the mix with those for the two materials fluidized separately, with flow velocities as similar as possible within our available data. In all 29 cases compared, the heat transfer coefficient for the mix was higher than the mean of the two components fluidized separately. In no case, however, was the difference judged to be of economic importance. Also, it is not clear what role charging plays in this enhancement effect. 


\subsection{Economic Assessment}

Our most recent experiments demonstrated that fluidizing particles of two contact-charging materials and applying an oscillatory electric potential difference between alternate immersed heat exchanger tubes does not enhance heat transfer significantly. Hence the concept has no economic merit. Fortunately, fluidized beds without electric field enhancement already offer good heat transfer properties to recover energy from warm waste gas streams, though they have not been widely deployed for such energy recovery. The one fluidized bed material found to show improved heat transfer with an applied oscillatory potential difference, quartz, is a poorer-than-average heat transfer material in fluidized beds. Hence it is not appropriate to use it and incur the disadvantages of high voltage and the arcing problems discussed in Section 2 of this report.

The use of a pair of bed materials which exhibit mutual charging, but with no oscillatory potential difference applied, offers the possibility of air cleanup along with energy recovery in a bed fluidized by a warm waste gas stream. This concept merits further consideration and testing. 


\subsection{References}

Colver, G. M. 1976. "Bubble Control in Gas Fluidized Beds with Applied Electric Fields." ASMEAIChE Heat Transfer Conference, St. Louis, Missouri, August 9-11. ASME pub. 76-HT-69.

Davidson, J. F., and D. Harrison. 1971. Fluidization, Academic Press, New York.

Elsdon, R., and C. J. Shearer. 1977. "Heat Transfer in a Gas Fluidized Bed Assisted by an Alternating Electric Field." Chemical Engineering Science 32:1147-1153.

Kunii, D., and O. Levenspiel. 1969. Fluidization Engineering, John Wiley and Sons, Inc., New York. 


\section{Distribution}

No. of

Copies

\section{Onsite}

12 DOE/Office of Scientific and Technical Information

6 W. Polansky, Director

Division of Advanced Energy Project

Office Of Basic Energy Sciences, ER-16 MS G-236, GTN

Washington, DC 20585

\section{Onsite}

\section{DOE/Richland Operations Office}

3 J. J. Sutey, K9-50

D. K. Jones, K8-50

R. F. Christensen, R3-72
No. of

Copies

Pacific Northwest Laboratory

22 E. G. Baker, P8-38

C. W. Enderlin, K7-15

J. A. Fort, K7-15

D. L. Lessor, K7-15 (8)

E. W. Pearson, K7-15

G. L. Roberts, P8-38

R. J. Robertus, P8-38

F. M. Ryan, K7-70

L. J. Sealock, Jr., K2-10

Publishing Coordination

Technical Report Files (5)

Distri.1 

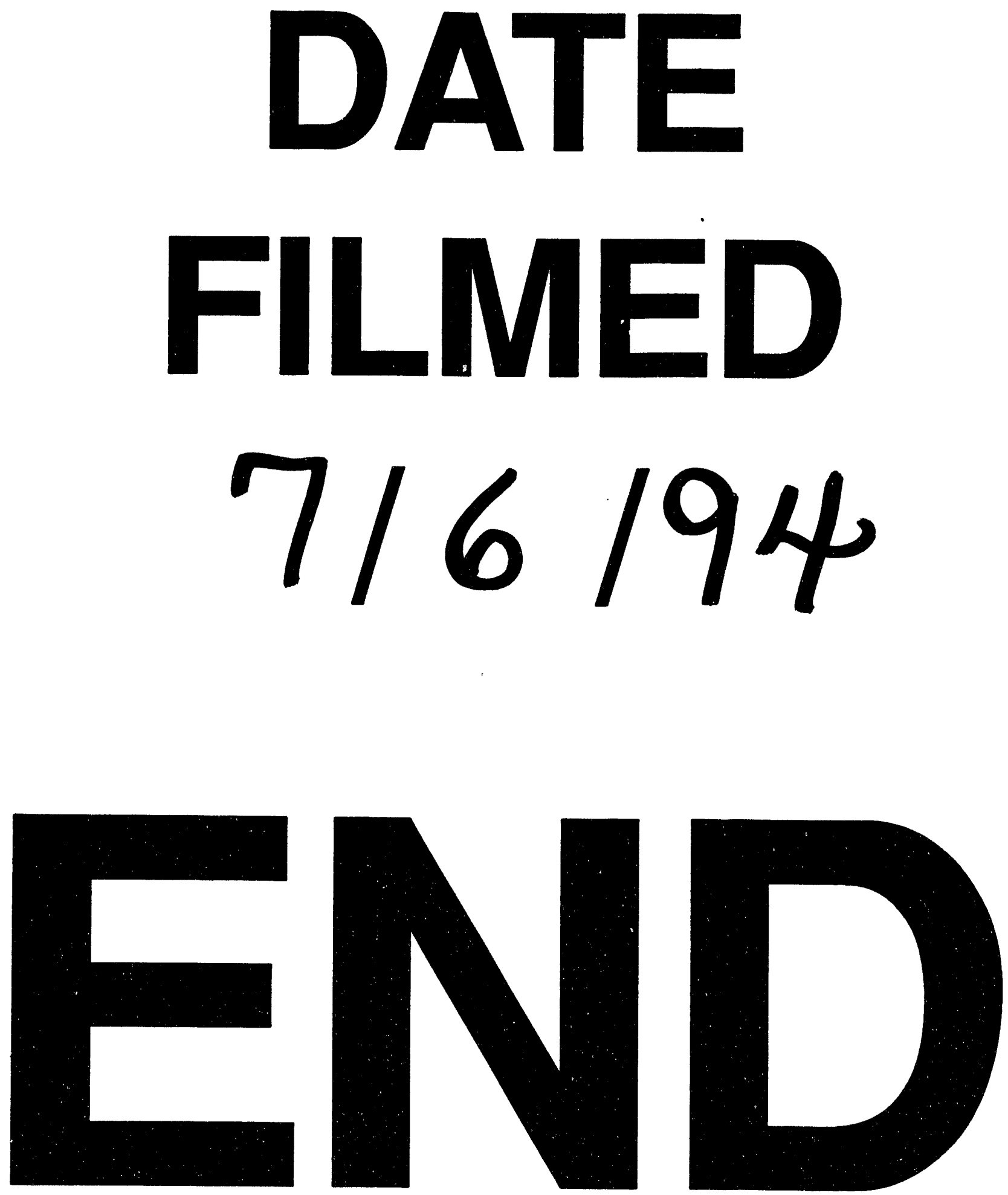


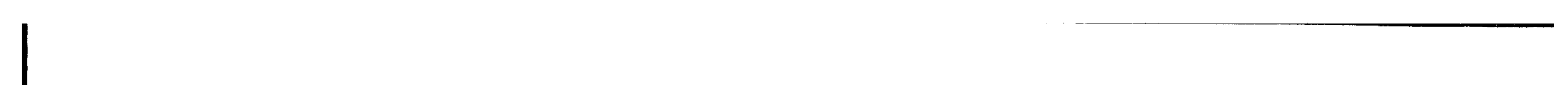
$-$ 